\title{
LA CARTA DE POBLAMENT DE PINYERES (BATEA, TERRA ALTA) (1280)
}

\author{
SUMARI
}

1. El lloc poblat: Pinyeres.- 2. El pas de Pinyeres de la jurisdicció de Miravet a la de Casp.- 3. Comentari a la carta de poblament.

Amb el present estudi històric vull presentar un document públic de poblament, el text del qual era desconegut fins al dia d'avui, i fer-ne el comentari històric $\mathrm{i}$ jurídic, tant pel que fa a l'instrument poblador com pel que respecta al lloc poblat.

El document és la carta de poblament del lloc de les Pinyeres, actualment despoblat, situat a la comarca de la Terra Alta, província de Tarragona, inclòs dins el terme municipal de Batea. El text que he descobert i ara presento és una còpia en paper, feta el 1758 per Gabriel Chiprana, notari reial de la vila de Casp, continguda en el lligall d'un plet civil de la Reial Audiència de Barcelona de «El Prior y Convento de Sn. Juan de Caspe del Reyno de Aragon. Contra el Fiscal de Su Magd. en lo Civil de la Rl. Audiencia del pnte. Principado de Cataluña.»' Aquesta còpia fou extreta del pergamí original, guardat antigament a l'arxiu del castell de Miravet i més tard integrat a l'arxiu del convent de Sant Joan de Jerusalem de Casp, segons consta per l'índex de l'arxiu de Miravet, conservat a l'Arxiu de la Corona d'Aragó, i per les dades notarials del notari Chiprana.

\section{EL LLOC POBLAT: PINYERES}

El llogarret de les Pinyeres o simplement Pinyeres, com l'anomenen els veïns de Batea i dels altres llocs de la rodalia, és situat a l'extrem occidental de la comarca de la Terra Alta, assentat a la riba dreta del riu d'Algars i a frec del riu,

1 Arxiu de la Corona d'Aragó (ACA), Reial Audiència, Plets Civils, núm. 13170, fols. 36 r. al $38 \mathrm{v}$. 
just on aquest, amb doble meandre, entra a Aragó pel terme de Favara. El lloc, que tingué terme propi i constituïa municipi, és a dues hores de camí de la vila de Batea, on els habitants de Pinyeres podien acudir a refugiar-se en temps de perill pel privilegi medieval de recolleta.

Suprimit el municipi l'any 1841 , el terme municipal restà agregat a Batea. El poblat, que no fou totalment deshabitat fins a la dècada del anys cinquanta, s'estén als peus del Tossal del Moro (270 m.), indret ocupat per les ruïnes d'un antic poblat ibèric ', a l'oest de les dues valls que travessen el terme i aiguabarregen poc abans de desguassar a l'Algars, la Vall de Pinyeres i la Vall dels Plans de Pinyeres. Les coordenades geogràfiques del lloc són 3053 30" de longitud E i 41 ${ }^{\circ} 00^{\prime}$ " de latitud $\mathrm{N}$ del meridià de Madrid.

El poblat de Pinyeres ocupa un indret que ha estat estratègic i cruilla de camins des dels temps més remots; la seva importància estratègica li ve sobretot del fet de trobar-se a la vora del curs de l'Algars, via natural vers l'Ebre i les terres de Lleida des de l'interior de la Terra Alta i des de Tortosa. Les torres de guaita antigues, esglaonades entre Tortosa i Lleida, seguien l'eix fluvial EbreSegre-Cinca i comptaven amb una línia col lateral que passava per Gandesa, Batea, Algars, Pinyeres, Favara, Maella i Nonasp i s'adreçava cap a Mequinensa. Eren torres ibero-romanes que aprofitaren els musulmans, de les quals algunes varen convertir-se en castells durant la dominació àrab i l'Edat Mitjana cristiana i donaren origen a viles i llocs, mentre que les altres mantingueren llur funció defensiva i vigilant; d'aquestes ens n'han quedat algunes restes arqueològiques i els topònims: el Coll del Moro del Calar de Gandesa, el Castell Nou, el Coll del Moro de Batea, les Torres, el Tossal del Moro de Pinyeres, el Castell d'Algars i les dues torres dreçades damunt els turons dels Barberans de Batea, encara subsistents, que dominaven el curs meridional i septentrional de l'Algars en tot el meandre que forma el riu als peus del castell de Sant Joan, entre el Mas de la Cova i el terme de Pinyeres.

Aquesta situació estratègica del poblat i terme de Pinyeres féu ja des de temps antics que hi vinguessin a parar o hi passessin diverses vies importants: el camí de Calaceit a Favara i el camí de Mas Alzines, que baixen de la zona dels poblats ibèrics de Calaceit, de Sant Antoni i del Tossal Redó; el camí de Pinyeres a Favara, que menava al Roquissar del Rullo, jaciment del Bronze, i a l'esmentada vila, on hi ha el conegut sepulcre romà; el camí de la Mascarosa; el camí de Pinyeres a Batea i el camí de la Vall Mitjana, que uneixen el poblat amb la via natural de la Vall Major de Batea i amb aquesta vila, des d'on, tot seguint vers Gandesa, el camí passa per les rodalies de la Punta de les Torres,

Oswaldo Arteaga, Josep Padró, Enric Sanmartí, El poblado ibérico del Tossal del Moro de Pinyeres (Batea, Terra Alta, Tarragona), Barcelona, 1990, Institut de Prehistòria i Arqueologia, Diputació de Barcelona, Monografies Arqueològiques, núm. 7. 
del Coll del Moro de Batea i no gaire lluny del Castell Nou i del Coll del Moro de Gandesa, indrets amb poblament ibèric. Totes, unes vies molt transitades durant els temps medievals i fins que s'ha imposat la circulació automobilística.

El terme de Pinyeres limitava pel sud amb el terme d'Algars per la vall de N'Albanell, pel nord amb el terme de Favara i partida de Vallbona, per l'est amb el terme de Batea i camí de les Gestingloses, i per l'oest amb el terme de Maella i partida de Gratallops. Dins d'aquesta partida, a frec de riu i al peu del Tossal del Moro de Pinyeres, des d'on es domina amb perfecció, hi ha la Costalena, abric de roca amb jaciment de l'Epipaleolític.

El lloc de Pinyeres, inclòs dins el terme del castell d'Algars durant l'època musulmana i els segles XII i XIII, fou atorgat a l'Orde del Temple pel Comte Ramon Berenguer IV, comptat entre els nombrosos llocs, viles, castells i termes donats el 24 d'agost de $1153 \mathrm{i}$ integrats dins el terme general del castell de Miravet:

...Ego Raimundus Berengarii, Dei gratia barchinonensis comes aragonensiumque princeps ac Tortose et Ilerde marchio, providens christiane utilitati et volens castrum de Mirabet quod divina tribuente clementia maximo labore cepi securis custodibus stabilire, libenti animo et spontanea voluntate, in remissionem peccatorum meorum, dono et concedo predictum castrum in manu venerabilis Pctri de Roera provincie et ispanie magistri dno. Deo et sancte ihrosolimitane milicie templi ac fratribus tam presentibus quam futuris inibi den servientibus, cum omnibus terminis suis videlicet ultra flumen Iberi in capud de baneoles ex parte Tevize serra serra sicut aque vertuntur versus Mirabet et vadit ad podios beçons usque ad terminum Tortose, et ex parte in qua castrum situm est dono illis beneçinen que dividit terminum cum Mora et ex inde protenditur terminus castri Mirabeti de Mora sicut vadit ad serram de Aschon, de inde sicut vadit ad Nonaspet deinde sicut vadit et ferit ad Favaram et deinde usque ad podium de Calcet et vadit usque ad Vilar de arenes sicut aque vertuntur versus rivum de Algars et deinde usque ad terminum de Caselas et de Buzot que sunt de termino de Orta et vadit ferire usque ad terminum Tortose, cum omnibus pertinent iis suis et castris et villis videlicet castrum de Algars et castrum de Batea (...)

Tot i que Pinyeres no hi és explicitat, la definició dels límits del terme del castell de Miravet i la menció dels termes de castell de Batea i Algars palesen la inclusió del poblat dins el territori concedit als templers pel Comte barceloní.

Allunyats com eren del castell de Miravet i situats a la riba de l'Algars, en

ACA, Reial Patrimoni, Mestre Racional, 541, fol. 78 r.

4 ACA, Pergamins de Ramon Berenguer IV, pergamí núm. 261. 
línia de frontera, el terme d'Algars i el de Batea amb els respectius castells i, per tant, el poblat i terme de Pinyeres, no foren ocupats efectivament pels templers potser per raó d'impossibilitat d'atendre amb suficient dedicació $\mathrm{i}$ eficàcia tan extens territori. El cas és que, arribat l'any 1181, veient el rei Alfons I el Cast l'abandó i l'oblit en què els templers tenien els termes d'Algars i de Batea malgrat llur gran importància estratègica, assumí ambdós castells sota el seu poder reial i els donà a poblar en sengles instruments jurídics, signats el mateix dia, a diferents pobladors i segons diferent fur.

Una carta de poblament dels castells d'Algars i de Batea l'atorgà el rei a un nombre indeterminat $\mathrm{i}$ innominat de persones, considerades encara com a eventuals pobladors, la qual cosa sembla demostrar que la carta reial de poblament fou feta en previsió de l'ocupació territorial i amb intenció de facilitar-la. En no tenir fixada la procedència dels repobladors indeterminats i potser pensant el rei que, per la situació geogràfica de l'indret i per la seva indefinició territorial respecte del Principat, els nous pobladors que acudirien a fixar llur residència a Batea i Algars serien aragonesos, aquesta carta de poblament la concedí ad fuerum Cesaraugustae."

La concessió del fur d'Aragó a Batea i Algars, com ja s'havia donat a la vila d'Orta (actualment Horta de Sant Joan) l'any 1165, afavorí les intencions expansionistes i dominadores dels aragonesos sobre les terres catalanes de la dreta de l'Ebre -batllies d'Orta, Ascó i Miravet- que duraren fins al regnat de Pere III el Cerimoniós. Així, l'any 1336, Pere III escriu a Bernat Jorba, jurisperit d'Orta, exigint-li que «donec questio que vertitur inter venerabilem Castellanum Emposte et homines de Orta super foro Aragonum fuerit terminata» no gosés aplicar el fur d'Aragó sinó que havia d'aplicar els Costums i Usos paccionals vigents des del temps del Temple: «(...) consuetudines et usancie pactionales juxta dictam provisionem et non forus Aragon tam in causis principalibus quam appellationum ibidem debeant observari (...)». " $\mathrm{La}$ provisió reial a què hom fa referència fou signada a Morella el dia 21 de juliol del mateix any. I l'exigència del rei al jurisperit d'Orta es fa a instàncies del Castellà d'Amposta per raó de la queixa de Guillem de Bas, veí de Batea, jutjat pel batlle d'Orta, que havia apel-lat a la cúria reial contra la sentència. El sobrejunter de Saragossa manta vegada obligava els pobles de les batllies catalanes a contribuir en els monedatges $\mathrm{i}$ a fer host i cavalcada amb els aragonesos, i els mateixos jurats i prohoms d'Orta, molt vel· leïtosos, contra la voluntat i la jurisdicció de llur comanador, sovint preferien atenir-se al fur d'Aragó més que als Costums d'Orta, inspirats en les Consuetudines Ilerdenses.

ACA, Cancelleria, Pergamins d'Alfons I, núm. 320.

"ACA, Cancelleria, reg. 587, fol. 3 r. 
Una segona carta de poblament atorgada per Alfons I de Lleida estant, com la genèrica ja esmentada, amb data del 25 d'octubre de 1181 o pocs dies després, 30 d'octubre, constituí com a poblador, a mb tots els drets i obligacions feudals, Bernat Granell. En aquest cas la carta fou atorgada ad fuerum Barchinonae. Es molt probable que el canvi de fur que hi ha entre la primera i la segona carta respongui a la condició catalana de Granell, poblador efectiu de Batea i d'Algars, i a la consideració de la catalanitat del territori -de l'Algars ençà- per part del rei Alfons, que no podia oblidar, malgrat tot, que usque ad rivum de Algars el seu pare l'havia donat al Temple sota el domini senyorial del castell de Miravet. El canvi de fur i el problema de la datació sorprengueren més d'un historiador, com Balari i Jovany i Miret i Sans. Font i Rius ha tractat el tema molt encertadament. 'I jo mateix li he dedicat un ampli estudi."

En ambdues cartes consten els mateixos límits dels termes de castell de Batea i d'Algars, que inclouen un amplíssim territori dins el qual és clar que restà integrat el lloc de Pinyeres: «(...) castrum de rivo de Algars cum omnibus terminis suis scilicet usque ad Nonasp et deinde sicut vadit et ferit ad Favaram (...) $) "$.

Sabem que desagradà molt als templers de Miravet que el rei prengués la iniciativa del repoblament sobre un territori que el seu pare els havia atorgat; per això, l'any 1182, immediatament després de concedir les cartes de poblament i donació d'Algars i Batea, demanaren a Alfons I una confirmació dels termes del castell de Miravet amb l'exigència que fes referència explícita a Batea i Algars, els dos castells i termes que eren motiu de la petició del document confirmatori. El rei hi accedí tot signant un pergamí a Osca el mes de març de 1182, el text del qual és aquest:

Notum sit scire volentibus quod ego Ildefonsus, Dei gratia rex Aragon comes Barchinone et marchio Provincie, dono et concedo in manu Berengarii de Avinione Magistri milicie in provincia et in partibus yspaniarum, domino Deo et venerabili domui militie templi et presentibus fratribus et futuris eiusdem domus terminos illos de Mirabeto usque in rivum de Algars. Predictos siquidem terminos iam dicti castri de Mirabeto et quidquid et quantum infra Mirabetum et rivum de Algars continetur et nominatim Bathea cum suis terminis dono et concedo sepe dicte domui et fratribus perpetuo sicut melius dici et intelligi potest ad comodum et bene prescripte domus et fratrum, de Bathea atamen intelligitur predicta donatio, si tamen sit infra prescriptos terminos. Actum est hoc apud Oscam mense martii,

'Josep M." FONT I RiUs, Cartas de población y franquicia de Cataluña, MadridBarcelona, 1969, vol. I pp. 229 i 798.

- Josep Alanyà i Roig La Carta de Donació a Bernat Granell. Doble fur i catalanitat de Batea a "La Vila Closa», (1988), núms. 8 i 9, pp. 91-97 i 103-110.

"ACA, Cancelleria, Pergamins d'Alfons I, núm. 321. 
anno $\mathrm{M}^{\circ} . \mathrm{C}^{\circ}$. $\mathrm{L} \mathrm{XXX}{ }^{\circ} . \mathrm{II}^{\circ}$. Signum + Ild.regis Aragon.comitis Barch.et marchionis Provincie. + Berengarius terrach.archieps. Sig + num Raimundi Gaucerandi. Sig + num Sancii de Orta. Sig + num Poncii de Cervilione. Sig + num Berengarii de Entencia. Sig + num Berengarii de Sanauja. Ego Guillelmus de Bassia, notarius dni. scripsi eiusdem mandato hanc cartam et feci hoc sig + num. "'

Amb aquest document els templers podien quedar tranquils i foragitar tot recel envers el rei i Granell. Batea i Algars eren del Temple $\mathrm{i}$ havien de sotmetre's al seu domini senyorial malgrat la carta de donació a Bernat Granell. Tanmateix, aquest encara exerciria el seu domini feudal efectiu sobre els termes esmentats durant uns quants anys, puix que no fou fins el 9 de maig de 1187 que cedí als templers el domini que havia rebut del rei Alfons. La cessió la fenen el mateix Bernat Granell, la seva muller Ermessenda illurs fills a mans de fra Giobert Eral magistro in partibus Yspanie i del preceptor de Miravet. Hi ba referència d'aquest document a l'Inventari del Castell de Miravet on llegim:

Item quoddam translatum factum Kls. junii anno dni.Millmo.CC. ${ }^{\circ}$ VIII super donationem factam per Bn. Granell et coniugem eius Ermessindam frati gioberto Eral q. tunc tempus erat magister in ptibus. Yspanie et preceptori Mirabeti et omnibus fratribus presentibus et futuris scilicet ipsum honorem quem habebant in Cast. ${ }^{\circ}$ d'Algario ut in Batea nec in suis terminis pro ut hec et alia in dto. translato continentur. "

El trasllat a què fa referència el Memoriale instrumentorum que erant in Mirabeto es conserva a l'Arxiu Històric Nacional en un pergamí defectuós. Pel seu interès n'oferim la transcripció:

Hoc est translatum fideliter translatatum Kls. junii Anno dni. M.CC.VIII ${ }^{\circ}$ Notum sit cunctis hominibus tam presentibus quam futuris quod ego Bernardus Granel et coniux mea Ermesen et filios et filias nostrorum, per nos et per omnes nostros presentes ac futuros damus et in donatione perpetua concedimus dno. Deo et beate Marie et milicie templi salamonis et fri.Gioberto Eral qui tunc tempus erat magister in partibus Yspanie.et fri.B.de Conchas preceptor Mirabeti, et in presentia plurium fratrum presentibus ac futuris ibidem Deo servientibus et successores eorum, videlicet ipsam honorem quod habemus vel habere debemus in Kastrum Algario vel in Batea nec in suis terminis. Sicuti nos habemus vel alicuius homo vel femina per nos et taliter quomodo nos habemus in cartula nostra pro acapite vel

16 AHN, OO, MM, Sant Joan de Jerusalem, Castellania d'Amposta, Batllia de Miravet, carpeta 306, núm. 4.

" ACA, Varia de Cancelleria, reg. 1, fols. 74 v. i 75 r. 
pro aprisione dni. regis Aragonensium, et hanc donationem firmiter facimus libenti animo atque gratuita voluntate ob redemptione animarum nostrarum ac parentum nostrorum et in remissionem omnium fidelium defunctorum sicut hoc melius dici vel intelligere potest ad proficium militie templi salomonis nec predictis fratribus. Et ego Bernardus Granel et coniux mea Ermesen nos et nostros per hanc donationem recepimus helemosinas militie templi ac predictis fratribus scilicet. CC.L. solidos monete barch. quos omnes vobis accepimus et nil ex eis nobis remansit, et sic predictam honorem quomodo superius scriptum est cum omnibus suis pertinentiis de nostro posse tradimus et in vestro dominio francham et liberam sine aliquo quod nos hic nec facimus retentum nec homo nec femina per nos vel per nostros in vestro dominio tradimus ad vestram voluntatem faciendam omnique tempore. Item facimus taliter hanc donationem, cum silvis et garricis et arboribus et pascuis et aquis, vieductibus et reductibus et cum egressibus et regressibus earum ut in perpetuum honorem aliquid nos hic requirere non possumus nec homo nec femina per nos et (...) ... arta firmiter permaneat. Actum est VII. idus madii, anno ab incarnatione dni. M.C. LXXX. VII. Sig+num Bernardi Granel. Sig+num Ermesendis (...) unanimiter qui hoc donum testibusque firmare rogamus. Sigtnum Bernardi. Sig+num Berengarii isti sunt filii nostri. Sig+num Raymundi Pebrada. Sig+num Petri calveti. Isti sunt testes huius rei. Sig+num Raymundi turris rubei. Sig+num Geraldi de Charcino. Sig+num fratris Falchonis. Sig+num fratris Bezoni. Sig+num Guillelmi Granel. Sig+num Sancie. Berengarius presbiter hec rogatus scripsit et anno quo supra et hoc signum + impressit. + Petrus sacerdos castri Orte. Sig+num Raymundi capellani ecclesie Orte. Signum Geraldi Tuset... nne. qui hec scripsit die et anno quo supra '?.

Malgrat el drets que els templers de Miravet exigien sobre Batea i Algars i, per tant, sobre Pinyeres, drets que jurídicament els corresponien, aquesta zona fou objecte de les pretensions del cavaller Artau d'Artusella, pare d'Elvira d'Artusella, muller de Guillem de Cervelló, i la mantingué sota el seu poder fins que l'any 1216 signà un compromís públic amb els templers. El document d'aquest compromís existia a l'arxiu del castell de Miravet:

Item aliud instrumentum in quo Artaldus de Artulosa mitebat castrum de Algars in manu fidelium, scilicet Pontii Dertusensis episcopi et quorumdam aliorum, sub tali condicione quod si dnus. rex judicaret quod prefatum castrum esset fratrum domus Templi, restitueret illud eis, et sub eodem juditio esset castrum de Batea. et si judicaret quod essent de jure ipsius Artaldi ipsa castra non tenerentur in aliquo fratribus ipsis ${ }^{13}$.

12 AHN, OO. MM. Sant Joan de Jerusalem, Castellania d'Amposta, Batllia de Miravet, lligall 306, núm. 7. Aquest document és citat per FONT I RIUS a Cartas de prablación..., I, pp. 798-799, notes 3 i 5.

13 ACA, Varia de Cancelleria, reg. 1, fol. 99 r. 
El text complet del compromís el trobem al foli 67 r. del registre 310 de la Cancelleria Reial de l'Arxiu de la Corona d'Aragó, en una còpia escrita en pergamí, que datem al segle XIV, sota el títol Compromissum inter templum et Artallum de Artusella super castris de Algars et de Bathea. El compromís, que fou fet el 20 de desembre del 1216, escrit de mà de Pere Roig, prevere del castell d'Orta, per manament del bisbe de Tortosa, deixà definitivament en poder dels frares del Temple els dos castells. Així, en virtut del compromís, Artau d'Artusella posà a mans del bisbe de Tortosa Ponç de Torrella, de Pere Garcés i Micaló de Frescà els castells de Batea i Algars amb la promesa de donar satisfacció justa als templers per tot el dany que ell els hagués pogut fer per causa de llur possessió, si aquesta havia estat injusta. Amb la condició, però, que l'assumpte s'havia de sotmetre al judici del rei d'Aragó Jaume I de manera que, si el rei i la seva cúria, d'acord amb el fur d'Aragó, consideraven que ambdós castells eren de la milícia del Temple, ell els retornaria a llur domini i els faria la devolució de tot allò que els hagués pres. El bisbe de Tortosa, com a componedor $\mathrm{i}$ àrbitre de la trobada, havia d'assignar als templers $\mathrm{i}$ al cavaller Artau un dia a reunir-se, que seria al cap de deu dies d'haver rebut una missiva seva tot convocant-los. Aquesta missiva havia de ser enviada un cop el rei hagués entrat a Aragó.

El rei i el seu tribunal decidiren a favor del Temple, amb la qual cosa Batea i Algars amb Pinyeres restaren per sempre més sota el domini del preceptor de Miravet. Per la força del compromís, Garcés i Micaló de Frescà es comprometeren a garantir la devolució dels castells al Temple per part d'Artau, tot jurant que ho farien acomplir o que ells mateixos personalment ho acomplirien sota la pena de ser traïdors al fur d'Aragó. Heus ací el text del compromís:

Notum sit cunctis hominibus quod ego Artallus de Artusella mitto castellum de Algars in manu fidelium scilicet Pontii dertusensis episcopi et Petri Garces et Machaloni de Freschano, et omne dampnum quod ego feci fratribus templi in castello illo et in terminis suis promito bona fide eis reddere sicut ipsi averare potuerint sub ordine suo, sub tali conditione, quod si dominus rex Aragonum et curia sua judicaverint per bonam consuetudinem Aragonis quod prefatum castrum est domus fratrum templi, firmiter mitto castrum illis in perpetuum, et omnes res ablatas eis reddam et reddi faciam, et sub eodem juditio domini regis sit castrum de Batea cum terminis suis. Si autem dominus rex judicaverit in curia sua quod illa duo castra sunt de jure meo, et quod non teneor illis ablata reddere, predicti fratres sint absque querimonia de me. Et dominus episcopus dertusensis assignet mihi et fratribus domus templi diem postquam dominus rex intraverit Aragonem, tamen missis litteris episcopi per decem dies antea. Et nos Petrus Garces et Machalonus de Freschano facimus homagium vobis fratri Bernardo de Campaniis preceptori Mirabeti ac totius Ripparie et vobis fratri Pontio Menescalia et aliis fratribus templi tam presentibus quam futuris, quod si Artallus prefatus hoc non impleverit 
sicut supra dictum est et scriptum, nos reddamus vobis castrum de Algars et restituamus vobis ablata plenarie. Sin autem simus traditores ad forum Aragonum et semper teneamur vobis vestra reddere. Actum est hoc XIII Kls. Januarii anno domini $\mathrm{M} \mathrm{CC} .^{\circ}$ sextodecimo. Era $\mathrm{M}^{\circ} \mathrm{CC} .{ }^{\circ} \mathrm{L} .{ }^{\circ} \mathrm{IIII} .^{\circ}$ in presentia Guillelmi de Solario canonici dertus. et Berengarii de Cambrils militis et Sancii de Saranana militis. et Iohannis de Ripolensi. et Petri de Taix et Gullielmi Garnerii et Guillelmi de Oiles et Berengarii de Montetornesio et multorum aliorum proborum hominum.

Petrus Rubeus presbiter castri Orte jussione dni. episcopi dertusensis hoc scripsit et hoc Sig + num fecit die et anno quo supra. ${ }^{14}$

En otorgar al Temple la jurisdicció senyorial sobre els castells de Batea i d'Algars, calia també deixar ben delimitats llurs termes, sobretot pel que feia als límits amb Nonasp, inclosa una part de la Vall de Batea, puix el castell, termes i vila de Nonasp havien estat en poder d'Elvira de Cervelló uxor quondam Guillelmi de Cervilione. ${ }^{15}$

Creiem que la possessió per Bernat Granell dels castells de Batea i d'Algars i, més tard, la possessió pels Artusella i Cervelló fins al compromís del 1216 foren la causa que entre les cartes de poblament $i$ donació atorgades pel rei Alfons el Cast (1181) i les cartes de poblament i establiment agrari d'Algars i Pinyeres s'escolés un segle. Mentrestant, a la comarca, entre els Ports d'Orta i l'Ebre, es produia una intensa activitat de repoblament que començà, potser fracassant a l'inici, amb la carta de poblament d'Orta atorgada pel rei Alfons I el 1165 ad fuerum de Saragoza. Així ho reconeix Font i Rius:

Constituye esta carta el primer testimonio de la actividad repobladora en la comarca de la Terralta y, en cierto modo, precedente de otras cartas otorgadas años después, especialmente en orden a la remisión al fuero de Zaragoza en diversos extremos. Las disposiciones de la misma intentaban la formación de una aglomeración urbana, estimulada por exenciones de impuestos de tráfico, garantías de seguridad en el mismo, regulación del mercado y de los riegos, e incluso con una incipiente ordenación penal y procesal. Ignoramos, con todo, el éxito obtenido por este int(nto, tal vez prematuro, de poblar una zona difícil e insegura todavía, pues no hay rcterencias posteriores a su efectiva colonización. En cambio se atestigua en 1166 la tenencia de su castillo por la familia de los Moncada, quienes encomendaban su custodia a otro caballero, Pedro de Subirats. No se mantuvo mucho tiempo el término de Horta bajo jurisdicción real, pues ya en 1177 pasaba su castillo, por donación del rey Alfonso, a la de los Templarios, quienes lo adquirían con todos sus

14 ACA, Cancelleria, reg. 310, fol. 67 r.

is ACA, Cancelleria, reg. 310, fols. 67 r.v. i 69 r. 
términos y pertenencias, derechos y percepciones, como libre y franco alodio. Esta posesión quedó consolidada en 1183, mediante cesión del mismo castillo y término efectuada por Ramon de Moncada al Temple y que concluirá sin duda definitivamente con los derechos yue pudiera ostentar dicha familia sobre tales lugares. ${ }^{16}$

Hom veu que un retard semblant al de Batea i Algars també va produir-se a Orta, perquè, malgrat la primitiva carta del 1165 i la ferma voluntat dels templers de Miravet de poblar el castell d'Orta, manifestada en l'instrument de concòrdia establerta entre els templers i el bisbe i el capítol de la Seu de Tortosa sobre drets, delmes i primícies, els frares del Temple no atorgaren carta de poblament als habitants de la vila d'Orta fins el 10 de gener del 1191 o 1192, deu o onze anys més tard que les cartes de poblament i donació del rei Alfons als pobladors d'Algars i Batea.

A partir de l'any 1181 , data de la concessió de les cartes de Batea i d'Algars, la comarca situada entre els Ports d'Orta, el riu d'Algars, l'Ebre i les serres de Pàndols i Cavalls, solcada per la Vall Major de Batea, el riu de la Canaleta o riu d'Orta, la vall de Baravall i la vall Bohona, comarca coneguda pels santjoanistes com la Castellania Alta perquè es trobava ultra serram, conegué una intensa activitat repobladora. Les condicions demogràfiques i de seguretat afavoriren el repoblament. Entre el 1191 i el 1210 els templers atorgaren cartes de poblament i establiment agrari a Orta (1191 o 1192), a Gandesa (1192 i 1194), al Pinell (1198 i 1207), a Batea (1205), a Ginestar (1206), a les Camposines (1209) i a Prat del Comte (1210).

Uns quants anys més tard, després d'un breu parèntesi en l'activitat repobladora, els templers de Miravet varen reemprendre-la amb l'atorgament d'instruments de poblament i establiment agraris a Vilalba (1224), a Gorrapte (1237), a la Vall de Batea (1244), a Gandesola (1248) i, després d'un altre parèntesi -aquest de trenta-dos anys-, a Algars (1280), a Pinyeres (1280), a Almudèfer (1280) i a la Pobla de Massaluca (1295). ${ }^{18}$ Pensem que aquest retard en la concessió de les cartes de poblament als llocs suara esmentats va produir-se perquè hi havia algun problema o impediment de tipus territorial o jurídic, com el que afectava Batea, Algars i la Vall de Batea, possessió efectiva dels Artusella, sense la resolució dels quals no era possible atorgar les cartes de poblament.

${ }^{16}$ Josep M. ${ }^{a}$ FONT I RIUS, ob. cit., I, p. 800.

17 L. Pagarolas, La Comanda del Temple de Tortosa: primer periode (1148-1213), Tortosa, 1984, pp. 265-267, doc. 87.

18 Josep M." FONT I RIUS, ob. cit. I, pp. 792-803. La referència a la carta de poblament de la Pobla de Massaluca és extreta de Pascual Ortega, La Carta de Población de la Pobla de Massaluca (1295), a “Acta Medievalia», 7-8 (1986-87) pp. 193-204. 
Un cop poblat, el lloc de Pinyeres quedà adscrit a la Batllia de Miravet juntament amb dotze viles més i llocs que es regien jurídicament pel dret català -Consuetudines Ilerdenses, Usatges de Barcelona- i pels Costums d'Orta (Gandesa) i els Costums de Batea (Batea, Pinyeres, Algars, la Vall de Batea i la Pobla de Massaluca) quan eren sota jurisdicció templera. En passar a la jurisdicció santjoanista, un cop extingit l'Orde del Temple, aquestes viles començaren a regir-se per les Constituciones Baiulie Mirabeti, promulgades l'any 1319. Es en el capítol 134 del text llatí de les Constituciones on trobem el lloc de Pinyeres entre els altres de la Batllia:

(...) in locis de Mirabeto, de Bonicenello, del Ginestar, de Raspera, de Pinello, de Salva terra, de Corbera, de Gandesia, de Mudeffer, de Bathea, de Villa Bona et del Algars et de Pinyeris (...). ${ }^{19}$

El lloc de Pinyeres, tot i constituir municipi propi i parròquia amb batlle, cort, consell de prohoms, jurats i rector, mai no fou gaire poblat. Així, segons el morabetí de l'any 1350, Pinyeres comptava aleshores trenta-vuit focs ${ }^{20}$; en el fogatge del 1378 els focs eren encara trenta-tres ${ }^{21}$; en un altre monedatge o morabetí del segle XIV - n'ignorem l'any-, hi figuren tan solament vuit cases ${ }^{22}$, fortíssima minva que atribuïm als perniciosos efectes de la pesta sobre els habitants del llogarret; segons el fogatge del 1497 hi havia també vuit focs ${ }^{21}$; el de l'any 1515 en compta només quatre ${ }^{24}$; el del 1533 en torna a comptar vuit ${ }^{25}$; i el llibre de la col-lecta de Tortosa i de la seva vegueria, pel que fa al dret de maridatge de l'any 1617, presenta el lloc de Pinyeres amb set focs i mig ${ }^{26}$.

L'època de màxima expansió del nucli urbà de Pinyeres coincidí amb l'esclat econòmic i demogràfic que tingué lloc durant el segle XVIII. Creixé el nombre de cases habitades i el terme fou totalment conreat. Encara a la darreria del segle XIX i la primeria del XX hi vivien estables, entre el nucli urbà i els masos -ressaltant-ne el Mas Nou i Santa Càndia, aquest amb capella pròpia dedicada a la santa màrtir - 900 habitants els quals, a mesura que avançava el nou segle, deixaven Pinyeres per un habitatge a les viles més grans de la rodalia. Alguns passaren a viure a Favara i Maella; els més, però, es traslladaren a la vila

19 AHN, Manuscrit llatí 944 B, fol. 11 v.

21) ACA, Reial Patrimoni, Mr. 2406, fol. 89 r.v.

${ }^{21}$ ACA, Reial Patrimoni, Mr. 2591, fols. 63 r. -67 r.

2 ACA, Reial Patrimoni, Mr. 2407, fol. 21 v.

23 ACA, Reial Patrimoni, Fogatges, reg. A-403.

24 ACA, Reial Patrimoni, Fogatges, reg. A-401.

25 ACA, Reial Patrimoni, Fogatges, reg. 2597.

26 ACA, Reial Patrimoni, Mr. 2601, fols. 94 v.-99 r. 
de Batea. Amb el decurs dels anys l'èxode dels pinyerencs anà creixent $\mathrm{i}$ això provocà el despoblament total de l'indret. El 31 de desembre de 1950 quedaven a Pinyeres solament nou habitants repartits en dues cases, havent-n'hi cent deu de desocupades dins el nucli urbà; $i$, a Santa Càndia, només restaven tres persones de la mateixa família que ocupaven una sola casa; els altres cent setanta masos ja eren deshabitats.

Fins al seu despoblament definitiu sembla que la història de Pinyeres ha estat marcada per un procés discontinu i alternatiu d'abandó $\mathrm{i}$ de retorn al poblat per part dels seus habitants. La causa d'aquest comportament demogràfic cal buscar-la en les condicions climàtiques i sanitàries i en les guerres que tantes vegades han assolat la nostra terra. Les males condicions higièniques del pla de Pinyeres les exposa Madoz:

Piñeras: aldea (...) situada cerca del río Algás, con buena ventilación y clima templado, aunque no de los más sanos, pues se padecen con frecuencia fiebres intermitentes. "?

\section{I també Emili Morera:}

Pinyeres (...) esta situat en un planer, essent poch sanitós per lo desenrotllo de febres intermitents en certes temporades anyals. ${ }^{28}$

El testimoniatge fefaent dels repetits despoblaments per causa de les guerres el trobem en el plet presentat davant l'Audiència Reial de Barcelona pel Prior i Convent de Sant Joan de Casp:

Joseph Bes, labrador, de Bathea, de setenta años de edad (...) Dixo (...) haver ohido a muchas Personas Viejas que en las Guerras del año 1640 havían visto que se havían aucentado los habitantes del termino de Piñeras por los trabaxos y miserias padezían y haver visto que muchos bolvieron despues a habitar en el y que despues de estas ultimas Guerras passadas se aucentaron por las calamidades padezían (...). ${ }^{29}$

Els indrets més notables de Pinyeres foren: l'església parroquial; el castell, avui inexistent, del qual només queda el sot de la cisterna construïda amb pedra picada; la casa rectoral; el petit cementiri; el forn del senyor; l'assut; els molins, moguts per l'aigua del riu d'Algars; el tossal de les forques; i la presó. Avui només queden el Molí de Figueres, el cementiri, la casa rectoral i l'esglesia; el tossal de les forques és l'indret ocupat per les ruïnes arqueològiques del poblat ibèric del Tossal del Moro.

27 Pascual MADOZ, Diccionario geográfico..., Madrid, 1849, XIII, pp. 51-52.

28 E. Morera Llauradó, Provincia de Tarragona, p. 472, volum de la Geografia General de Catalunya, dirigida per CARRERAS CANDI.

29) ACA, Reial Audiència, Plets Civils, núm. 13170, fol. 56 r. 
L'església parroquial, dedicada a la Transfiguració de Jesucrit, presideix les cases del llogarret des de la solellosa esplanada on és ubicada, a la banda de ponent del poblat i amb la façana orientada al migdia. Al davant hi ha una gran plaça, la plaça del lloc, una part de la qual, enfront de la porta del temple, era ocupada pel castell desaparegut.

L'església és de planta rectangular, amb els murs laterals de $17^{\prime} 50 \mathrm{~m}$. de longitud i els de la capçalera i absis de 7’40 m. A l'interior hom pot admirar la gran bellesa amb què s'imposa la perfecció senzilla de la construcció, l'harmonia de línies i proporcions que revela el cànon de la secció àuria i el joc de plans, jugant amb la llum i l'ombra, que resulta de la distribució dels arcs d'ogiva. La nau és també un rectangle pur sense disposició absidal, originalment dividit amb perfecta simetria i proporció per nou arcs diafragmàtics que travessen l'àmbit de nord a sud. Els arcs, formats per carreus atallantats de $0,55 \mathrm{~m}$. de gruix, arrenquen de terra mateix i, a uns $0^{\prime} 50 \mathrm{~m}$., les impostes presenten una motllura que recorda l'àbac dels capitells romànics, si bé aquesta motllura és senzilla, sense decoració.

Els arcs, que s'eleven fins als 3’85 m. d'altura i en tenen 5’35 de llum, són apuntats, però la seva línia és molt pròxima encara als arcs de mig punt del romànic, de manera que l'ogiva és lleument insinuada, la qual cosa palesa el seu estil de transició; així, creiem que cal atribuir a la primeria del segle XIII la data de la construcció del temple.

Els espais entre arcs medeixen tots exactament 1'25 m. Almenys així fou originàriament, perquè amb el temps el recinte patí diverses modificacions que provocaren la retallada o supressió de dos arcs. A diferència de les altres esglésies de la mateixa època i estil, repartides per la Terra Alta, la de Pinyeres no eleva els arcs fins a la línia de coberta, sinó que al damunt d'aquests segueix aixecant-se una paret de $2^{\prime} 30 \mathrm{~m}$. que, arc per arc, va compartimentant l'església per la part alta, tot donant-li una especial bellesa i també ferma seguretat arquitectònica. Aquesta característica la fa, entre totes, la més alta:

La més gran del seu gènere i en certa manera la més monumental (...) de forma que resulta molt més llarga. També les sobrepassa totes en alçada, no perquè els arcs siguin més alts, que no ho són, sinó perquè damunt seu continua una paret de més de 2 metres. ${ }^{30}$

A l'exterior, el mur que mira a tramuntana mostra quatre potents contraforts que reben la descàrrega de forces dels arcs més propers a la porta. $\mathrm{Al}$

30 Enric Ventosa i Serra, Esglésies singulars de la Terra Alta, Tarragona, 1986, Institut d'Estudis Tarraconenses Ramon Berenguer IV, Diputació de Tarragona, p. 41. 
mur que mira a migdia, que és el de la façana, no hi ha contraforts separats sinó que fa llur funció un contrafort de base que és de fet un engruiximent del mateix mur, estès sense solució de continuiitat des de la cantonada absidal fins a la portalada.

A la façana de l'església hi ha dos elements constructius que destaquen: l'espadanya i la portalada. L'espadanya, dreçada damunt la portalada, consta d'una base i dos cossos, amb dos ulls més grans $\mathrm{i}$ un altre de més petit que permeten donar cabuda a dues campanes mitjanes i a una altra de petita; el cos superior, centrat pel buit per a la campana, és el coronament del campanar a manera de frontó. Els tres arcs de les obertures són de mig punt. La portalada, obra de pedra picada, correspon a l'estil de transició i la componen vuit dovelles grans que formen arc circular de mig punt, ornat amb guardapols motllurat descansant damunt els salmers i dues impostes també motllurades.

Aquest tipus de portalada l'hem trobat en diverses edificaciones construi-des entre la segona meitat del segle XII i els cinc primers lustres del segle XIII i sembla que cal lligar-lo amb la tasca repobladora i reconstructora dels templers, puix que el trobem a la porta de l'església del castell de Peníscola, a la de l'església del castell de Miravet, a la de l'església de la Mare de Déu de Dalt de Benifallet i a la porta de l'antiga capella del castell de la Suda de Tortosa, que mostra el Crismó a ia pedra clau.

El mateix tipus de portalada també és present al monestir de Benifassà, a Bel i a altres pobles de la Tinença i Ports de Morella, com a Catí. Així mateix és d'aquest estil, tot i que ogivada, la porta de l'església de Paüls. i podem esmentar encara, a tall de mostra representativa, les portalades de l'església de la Canyada de Beric, de l'ermita de Sant Vicent d'Aguiló, del temple de la Cirera, de l'església de la Guàrdia dels Prats, de Pontils, de les Piles i les dues portes de la façana de l'antiga casa dels Sobies a Tàrrega. A la comarca, però, la portalada de Pinyeres és única.

La coberta de l'església fou resolta amb una tècnica constructiva que és comuna a totes les edificacions religioses de la Terra Alta que varen aixecar-se durant la darreria del segle XII i la primeria del XIII. És la tècnica de lloses saltacavallades suportades per arcs diafragma. Aquesta tècnica arquitectònica, molt original, permetia de fer els murs menys gruixuts que en les construccions romàniques, ja que no havien d'aguantar l'empenta de la pesant volta pètria. Entre el romànic i el gòtic, aquesta tècnica solucionà el problema físic de les forces de descàrrega de la coberta i dels arcs mitjançant l'arrencada d'aquests des dels mateixos fonaments de l'edifici i amb uns contraforts exteriors ben formats. La simètrica disposició dels arcs diafragmàtics, molt pròxims els uns als altres, permetia de repartir el pes de les lloses de la coberta.

Les proporcions de l'església de Pinyeres s'ajusten a la secció àuria, i així ho fa notar Fuguet i Sans: 
Respecte a les proporcions, apreciem les mateixes relacions basades en el nombre d'or; a la planta s'empra una combinació típica que s'aplica quan es vol allargar un rectangle auri consistent en afegir-li el quadrat del costat petit ${ }^{31}$.

Enfront de l'església, separat d'aquesta per l'esplanada de la plaça, hi havia el castell. Avui, d'aquesta edificació no en queda res; fou destruïda i els seus carreus, desmuntats, foren aprofitats pels habitants del llogarret per a llurs cases i marges com es pot comprovar. A l'indret que ocupava el castell, en un pla que s'estén als peus d'un petit aturonament, al mateix nivell de l'església i per damunt de les cases del lloc, només s'ha conservat, obrada en pedra picada, l'antiga cisterna de perímetre circular que degué estar protegida per un brocal.

De les declaracions de les persones que encara conegueren l'edifici, ja molt atrotinat, en podem deduir que el castell de Pinyeres no era una fortalesa muntana, com els d'Algars, Batea i Almudèfer, sinó un casal fortificat on hom podia residir de manera continuada, com els castells de Nonasp, d'Herbers i de Gandesa, i el casal fort dels molins d'Algars. Malgrat les diverses transformacions que s'hi degueren fer en el transcurs del temps, devia conservar-se encara l'estructura arquitectònica antiga, perquè en el segle XVIII hi ha referències explícites a la barbacana i s'atribueix la seva existència a temps immemorial; així ho declarava Joan Baptista Sunyer, llaurador de Batea, l'any 1759:

...lo que el testigo dixo saber por haver visto de todo el tiempo de su acuerdo y haverlo ohido dezir a sus mayores de forma que no ay memoria de hombres en contrario no solo oy en dia y en el año 1753 sino también de antes y despues en el dicho termino de las Piñeras scito en el Principado de Cataluña ha existido y existe una $C a s a$ muy grande que contiene uno vulgarmente uno vulgarmente llamada y se llama Barbacana delante la qual ha havido y ay un Patio, o Plaza que se nombra y ha nombrado siempre la referida casa o edificio el castillo lo que ha visto muchas vezes y oyo dezir siempre a sus passados y mayores lo que es muy publico y notorio en la villa de Batthea y demas circumvezinas ${ }^{32}$.

Segons Josep Aguiló, llaurador i veí de Batea, el castell havia estat adobat i reconstruït:

(...) a la qual casa o edeficio siempre se ha nombrado y nombra el Castillo

"Joan FUgueT I SANS, L'arquitectura de les capelles templeres a la Catalunya Nova, Primeres Jornades sobre els Ordes Religioso-Militars als Països Catalans, Montblanc, 1985. Publicat a "Aplec de Treballs», 9, Montblanc, 1989, Centre d'Estudis de la Conca de Barberà, p. 38.

$\because$ ACA, Reial Audiència, Plets Civils, núm. 13170, fols. 64 v.-80 r. 
haviendosele el testigo echo componer y reedificar de orden del Prior y Convento de Sn. Juan de Caspe lo que es muy publico y notorio en la pnte. Villa de Bathea y demas circumvezinas".

Jeroni Balaguer, també llaurador de Batea, un altre testimoni, declara la causa del mal estat del castell:

(...) porque en las guerras se quemó, se compuso y reedifico de orden del Prior y Convento de Sn. Juan de Caspe ${ }^{34}$.

El castell havia estat lloc de residència del batlle de Pinyeres i allí hi tenia la cort de justícia, on exercia els actes jurídics de mer i mixt imperi en nom del senyor baronal. Era també el lloc on s'arreplegaven els fruits i censos que pertanyien al senyor. Per tal de recollir els delmes i censos senyorials, el senyor jurisdiccional nomenava un arrendador, que acostumava a ésser veí de Batea: això vol dir que batlle $\mathrm{i}$ arrendador havien de compartir les estances del castell $\mathrm{i}$ aquesta situació fou causa de friccions entre ambdós representants del senyor. Així succeí l'any 1762, temps en què era batlle Pere Altés i arrendador Miquel Vaquer, tots dos de Batea. Miquel Vaquer presentà al batlle un requeriment notarial per mitjà del notari de Batea Jaume Ferrer queixant-se de

cómo con asistencia del Dr. Pedro Tarragó consulente por Vmd. assumpto y actuario franco. Vaquer Notario hizo una sumaria contra esta parte de Miguel Vaquer vezino Labrador de la Villa de Bathea, la que en fuerza de recurso hecho por este embio Vmd. a la Real Sala Criminal de la Real Aud. " quien en su vista proveyó que esta parte fuesse libre del arresto, y en consequencia mandado a Vmd. para que entregara la llave del Castillo y todos los frutos estavan en dho. Castillo propios de esta parte como Arrendador, todo lo que a Vmd. se le notificó e hizo parte en virtud de copia de la Real provisión. Y como no obstante todo lo referido no haya dudado Vmd. en no obedecer lo mandado por dicha Real Sala resistiendosse en no querer entregar la llave y frutos de que resulta grande daño y perjuhizio estima en 500 lls. a pagar de sus propios bienes y aplica a los Reales erarios de su Ex." y Real Sala Criminal, le requiere por una, dos, tres y quantas vezes son menester, que sin la menor demora le restituya o entrede la conformidad estavan al tiempo que $\mathrm{Vm}$. le quitó la llave (...) ${ }^{35}$

El dia 29 de març, el batlle de Pinyeres, abans de lliurar la clau del castell a

${ }^{33}$ Ibidem, fol. $68 \mathrm{v}$.

if Ibidem, fol. $64 \mathrm{v}$.

is Arxiu Històric Provincial de Tarragona (AHPT), Batea, Notari Jaume Ferrer, Manual de Contractes, any 1762, caixa 5, núm. reg. 2598, fols. 6 v. -7 r. 
l'arrendador Miquel Vaquer, féu inventari dels béns que hi havia dins la casa forta en presència de dos testimonis, Francesc Galcerà, pastor, i Roc Carceller, llaurador, $i$ en poder del notari de Batea, Jaume Ferrer; els béns inventariats eren fruits del camp recollits i emmagatzemats dins el castell, pertanyents al delme i censals de Pinyeres:

En el saguan de dho. Castillo: Primo en una portadera mal cubierta algunos dos cántaros y medio de vino. Item en una tabla de olivas engranerada cosa de algunas cinco medidas bien cumplidas. En la sala: Primo aluvias nueve quartales y dos almudes. Item, trigo puro de diezma, nuebe quarteras, quatro quartales, y un almud. Item, trigo algo centenoso, llamado de censos o peytas doze quarteras, ocho quartales y un almud. Item, zebada de peytas, una quartera. Item, avenoso de diezma, una quartera, quatro quartales y un almud. Finalmente centeno de Diezma, una quartera y dos almudes $(. . .)^{36}$.

El lloc tenia també una presó, que no devia ser gaire segura, puix que els detinguts més perillosos eren traslladats a la presó de Batea. Així es desprèn de les declaracions de Jeroni Balaguer, llaurador de Batea, de 70 anys d'edat, testimoni dels santjoanistes en el plet portat davant la Reial Audiència de Catalunya contra el fiscal del Civil de la mateixa Audiència:

(...) en el año dos o tres (1702 ó 1703) cogió el Bayle del dho. termino de Piñeras una partida de Gitanos que robaron en aquel termino de Piñeras y los puso en aquella Carcel y porque entonces no era muy segura los traxo el dicho Bayle a la Carcel de la Villa de Bathea (...) assimismo ha visto hazer y componer la Carcel de dicho termino de Piñeras ${ }^{37}$.

Per l'acta de presa de possessió del lloc, aixecada pel notari de Batea Vicent Català, que va celebrar-se amb la solemnitat acostumada el 31 d'agost del 1576, tenim notícia del forn del senyor:

(...) idem Dnus. Petrus de Luna, ac Dnus. Joannes Cortés una mecum dicto Notario testibusque praedictis assistente semper in hiis eodem Petro exeuntes a dicto Castro et Monte, fecerunt iter ad furnum dictae villae constructum in dicta villa infra dictum castrum, et ibidem existentes in praesentia praedictorum omnium, idem de Luna tradidit possessionem dicti furni sepe dicto Dno. Joanni Cortés in modum sequentem: Quod constituti ante portale patii praedicti furni

36 AHPT, Batea, Notari Jaume Ferrer, Manual de Contractes, any 1762, caixa 5 , núm. reg. 2598 , fol. 22 r.v.

"ACA, Reial Audiència, Plets Civils, 13170, fol. 64 v. 
accepit eundem Joannem Cortés per manum ejus dexteram, et immissit eum in eodem patio, ipseque vero foras exivit, eodem Cortés intus in dicto patio remanente, mittente et extrahente de eodem furno quemdam panem in signum verae et realis possessionis, dixitque, et exposuit quod praedicta nedum re, sed etiam corpore et animo possidere intendebat nomine ac vice suis ac dicti Conventus Caspis principalis sui ${ }^{38}$.

La mateixa acta ens dóna notícia del tossal de les forques del lloc de Pinyeres, que era l'indret conegut com a Tossal del Moro, una elevació de 270 $\mathrm{m}$. que domina el poblat $\mathrm{i}$ tot el terme, indret ocupat per un antic oppidum ibèric, on hi havia dreçats de manera permanent els instruments d'enforcament, que eren de pedra:

Et illico (...) in praesentia dictorum hominum et singularium dicti loci in dicto loco ibidem existentium, fecit ibidem construi quasdam furcas ligneas, et sic confectis, in eisdem appendi jussit quasdam manicas, et eas appensas iterum ab eadem furca amoveri voluit, et ad uberiorem cauthelam in signum verae et realis possessionis totius jurisdictionis dictae villae jussit in furchas lapideas, quae jam confectae erant in sumitate cujusdam montis qui est ante faciem dictae villae, appendi quamdam herbam magnam vulgo nominatam Botja ${ }^{39}$.

Entre el castell i l'església hi havia la plaça del lloc, indret de trobada dels veïns $i$ on era costum de celebrar els actes públics municipals com els consells generals de veïns $\mathrm{i}$ els actes col·lectius de vassallatge $\mathrm{i}$ homenatge al senyor baronal. Així fou fet, seguint el costum, quan, en nom del Prior i Convent de Sant Joan de Jerusalem de Casp, prengué possessió de Pinyeres el reverend Fra Joan Cortés, hospitaler.

Et successive ad alios actus minime se divertendo, recedentes a dicto furno recta via accesserunt ad quandam plateam quae est ante portam ecclesiae sepae dictae villae de les Piñeres, presentibus semper in his me dicto notario et ibidem presentibus eisdem Dnis. Petro de Luna, et eodem Dno. Joanne Cortés, convocata, congregata hac de causa tota universitate hominum ac singularium ejusdem villae de les Piñeres de mandato Michaelis Viver bajuli ac judicis ordinarii dictae villae de les Piñeres ${ }^{40}$.

Pinyeres gaudia de temps immemorial d'un assut i d'una sèquia per a

38 Ibidem, fol. 22 r.v.

39 Ibidem, fol. $22 \mathrm{v}$.

${ }^{40}$ Ibidem, fol. $22 \mathrm{r}$. 
regar les terres planeres més pròximes al nucli poblat $\mathrm{i}$ al riu d'Algars; sèquia $\mathrm{i}$ assut sobre els quals, abusivament, el Dr. Alcoriza, Procurador Jurisdiccional de la Castellania d'Amposta, exigia tenir drets en virtut del quals hi féu actuacions interessades en benefici propi. Aquests drets pretesos foren contestats pels santjoanistes del Convent de Casp i les actuacions que l'Alcoriza dugué a terme sobre la sèquia, assut $i$ aigües foren denunciades a la Reial Audiència de Catalunya. D'aquí s'originà el plet civil dels santjoanistes de Casp contra el fiscal del civil de la Reial Audiència, puix que aquest havia abonat les abusives pretensions d'Alcoriza. El plet va iniciar-se l'any 1753 i té l'interès d'oferir moltes dades interessants sobre el llogarret de Pinyeres i, sobretot, de contenir una còpia autèntica de la carta de poblament, fins avui desconeguda.

Segons la Impugnación del Escrito Dado por Dn. Pedro Alcoriza en 18 de junio de 1798, feta pel Prior i Convent de Casp,

El Doctor Alcoriza (...) entra suponiendo que tiene quieta, y pacífica posession, seu quasi de conducir las Aguas del Río Algás para el riego de sus propias tierras que tiene en el termino de Piñeras por medio de la propia Azequia que á sus Costas ha construido, y en la conformidad que lo ha practicado de muchos años.

Esta suposición preliminar de Alcoriza que hace en su escrito es falsa; y para la maior claridad, se deve sentar que el Convento de Sn. Juan de Caspe tiene de immemorial en su termino de Piñeras una Azequia por donde conduce el Agua para regar las tierras susceptibles de este beneficio. La Agua de esta Azequia se toma del Rio Algás por una Azud de estacada, construida también de immemorial en el rio Algás como quatrocientos noventa passos poco más o menos fuera del termino de Piñeras, y en la parte superior del Río, sobre esta Azud vieja de estacada que estava construida de immemorial, intentó edificar el Dr. Alcoriza como trescientos passos más arriba de ella otra Azud, ó Presa, y desde ella ha abierto como ochocientos y diez passos de Azequia nueva por donde conduce el Agua hasta hecharla, e introducirla en la Azequia Vieja ${ }^{41}$.

El dret a les aigües de l'Algars, a la sèquia i a l'assut, que els de Pinyeres i els seus senyors feudals tenien des de temps immemorial, es remuntava a la carta de poblament $i$, sens dubte, més enllà encara, al temps anterior a la reconquesta cristiana. Dret que recollí l'instrument poblacional: «Damus et concedimus et in perpetuum tradimus vobis (...) ad populandum totum nostrum Mansum vocatum vulgariter de les Pinieres qui est in termino de Algas (...) cum hortis hortalibus (...) aquis (...) ac piscationibus».

4 ACA, Reial Audiència, Plets Civils, núm. 13170, quadern de 6 folis que es troba solt i adjuntat dins el volum del plet, sense foliar. Quadern Impugnación, s.f. foliació pròpia, fol. 1. r.v. 
Els drets immemorials i l'avantatge que l'assut fos d'estacada queden exposats clarament dins el text de la impugnació contra el Dr. Alcoriza:

De tiempo antiquissimo immemorial han tomado el Agua por la Azud y Azequia vieja para regar sus tierras los terratenientes de Piñeras y aunque esta Azud de estacada esté expuesta a descomponerse algo con alguna avenida del Río, con la misma facilidad, prontitud, y poco gasto se bolvía a reparar, tomando siempre de ella la Agua necessaria para fertilizar sus tierras, de forma que si en el Río venía copia de Agua tomavan toda la necessaria, y si venía poca, la recogían toda con la estacada, siendo incierto lo alegado, de que de muchísimo tiempo apenas entrava agua en la Azequia vieja, ó que era mui poco aunque abundara en el Río ${ }^{42}$.

Arran de greus epidèmies i sobretot de les guerres, el llogarret de Pinyeres sofrí diversos despoblaments, el més greu dels quals, almenys dels que tenim notícia històrica, fou el que tingué lloc com a conseqüència de la guerra de Castella contra Catalunya l'any 1640 sota el regnat de Felip IV. Així es desprèn de les declaracions de diversos testimonis semblants a la de Jeroni Balaguer, de Batea:

Dixo que lo expressado en dho. Cap. ${ }^{\circ}$ era verdad lo que el testigo dixo saber por haverlo ohido dezir a sus Abuelos y Personas muy viejas del año mil seiscientos quarenta y de estas últimas Guerras haverlo visto el testigo como todos lo dexaron hiendoze unos a la villa de Calaceite, otros a la de Maella y otros a la presente Villa (de Batea) y haver el testigo conocido a algunos Bautizados en la Pila del Bautismo del termino de Piñeras. ${ }^{43}$.

Després d'aquest despoblament i dispersió dels habitants de Pinyeres, els santjoanistes de Casp decidiren repoblar el lloc l'any 1652:

El Iltre. Convento de Sn. Juan de Caspe Dueño Territorial después que por la vicisitud de tiempos calamitosos en lo Antiguo, vio despoblada la Villa de Piñeras, la procuró repoblar por el año 1652 cediendo a los nuevos vezinos el util de las tierras, Aguas, y pastos, quedando a cargo de los mismos vezinos el mantenerse la Azequia, y Azud, como en efecto desde dicho tiempo hasta de presente ha corrido de cuenta de los mismos la reparación y manutención de estas obras. ${ }^{44}$.

42 Ibidem, quadern Impugnació, s.f., foliació pròpia, fol. 2 r.v.

43 Ibidem, fol. 64 i ss.

4t Ibidem, quadern Impugnació, s.f., foliació pròpia, fol. 2 v. 


\section{El PAS DE Pinyeres DE LA JURISDiCCiÓ DE MiRAVET A LA DE CASP}

El lloc de Pinyeres, com Batea, Algars, Almudèfer i la resta de viles i castells de la Terra Alta, fou donat a l'Orde del Temple i al castell de Miravet pel Comte Ramon Berenguer IV i formà part del seu terme general en virtut de la donació feta «in manu venerabilis Petri de Roera provincie et ispanie magistri dno. deo et sancte ierosolimitane milicie templi», signada el 25 d'agost de 1153, un cop conquerit als moros amb no poques dificultats el "Castrum de mirabet quod divina tribuente clementia maximo labore cepi»" ${ }^{\text {s. }}$.

Com a pertanyent al terme del castell de Miravet, Pinyeres fou poblat pels frares del Temple, que senyorejaven la batllia des de la fortalesa de la Ribera d'Ebre, i va regir-se sempre pels costums de Batea i pel dret català sota el Temple; més tard s'atengué, ja sota el domini de l'Orde de l'Hospital, als Costums de la Batllia de Miravet. Així ho fa constar Pere Real, síndic de la universitat de Batea, en els capítols presentats contra Jeroni de Heredia en el plet mogut contra aquest infançó per raó del molí d'Algars als inicis del segle XVII:

1. Ponit que en lo any Mil trescents y desanou a tres de las Nonas de juny los tunc Castella de Amposta y frares del orde de Sant Joan de hierusalem congregats e aiustats capitularment en lo Castell de la Vila de Gandesa, Castellania de Amposta, concediren als vehins y habitadors de las vilas y locs de la ballia de Miravet que llavors eran y per temps seran ço es als de Miravet, Beniçanet, Ginestar, Rasquera, Salvaterra, lo Pinell, de Gandesa, Corbera, de Batthea, de Vilabona y de Algas y los de Pinyeres un libre de Costums o Privilegis lo qual volgueren dits senyors en ditas Vilas y lochs haver de esser tenguts per lleis y de aquelles haguessen de usar y usasen en tota ocasió loch y temps ${ }^{46}$.

Durant el segle XIV, essent Gran Mestre de Rodes fra Joan Fernández de Heredia, la comanda de Casp va convertir-se en batllia i el convent de l'Hospital d'aquesta vila aragonesa passà a tenir molta importància, tanta que el batlliu de Casp fou una de les dignitats més importants de l'orde dins la Corona d'Aragó. Pinyeres, juntament amb la vila de Nonasp, esdevingué propietat del Convent de Casp des de mitjan segle XV. Fins aleshores havia format part de la batllia de Miravet amb els mateixos drets i deures que les

is ACA, Pergamins de Ramon Berenguer IV, núm. 261.

${ }^{46}$ ACA, Reial Audiència, Plets Civils, núm. 7655, fol. 3 v. 
altres viles i llocs, i el seus representants acudien també a Gandesa, com els de les altres viles, per fer o celebrar Junta de Batllia.

Fra Joan Fernández de Heredia fundà $\mathrm{i}$ dotà de propietats i censos el convent santjoanista de Casp de manera que res no manqués a la comunitat hospitalera per al sosteniment ordinari ni tampoc per al servei religiós. Així ho feren constar al Gran Mestre i Convent de Rodes Fra Joan Cortés, Prior del convent de Casp, i Fra Pere Perandreu, frare de dit convent i procurador seu, en demanar que hom els respectés i concedís sense destorb els drets i censos que tenien sobre Nonasp i Pinyeres; originàriament, la dotació del convent era constituida per la vila de Jatiel i les heretats, cases i possessions de Samper de Calanda. El text de la petició, inclòs dins la butlla magistral de Fra Joan Levesque de la Calière, datada a Malta el 24 de març del 1574, és ben explícit:

Illmo. et Rmo. Sr. sancto y General Capítulo, Fr. Joan Cortés Prior del Convento de Caspe, y Fr. Pedro Perandreu fraÿle del dho. Convento de Caspe y Pror. del dho. Convento, servidores y obedientes subditos de V.S. Illma. y de esta Sta. Religión, humildemente suplicando de su parte y dho. Convento expone: Cómo haviendo sido fundado el Monasterio susodicho por la felice memoria de nro. Sor. Illmo. Fr. Dn. Juan Fernández de Heredia, Gran Maestro de esta Religión, y dotado ansí de ornamentos, Cruzes y Cálices, jocalías y rentas convenientes y decentes al Servicio Divino, como para el sustento ordinario de dha. Casa, y Religiosos, entre otras cosas le dotó de un lugar llamado Exatiell, y de catorse Casas y vasallos, y quinze quiñones en el Lugar de Sanper (... ${ }^{47}$.

Entre els anys 1433 i 1444, durant el temps del Castellà d'Amposta Fra Joan Baptista Vilarregut, aquest Castellà, mogut per la millor conveniència i interès de la Castellania i dels seus membres, amb un acord unànime, féu la permuta de les possessions originàries de Jatiel i Samper de Calanda per les viles de Nonasp i Pinyeres, que passaren així de la jurisdicció de Miravet a la de Casp:

(...) posseyendo dho. Convento las sobredhas, rentas, sin embargo alguno avino que viviendo el Illtre. Sr. Dn. fr. Juan Baptista Villarregut Castellán de Emposta y visto que convenía mucho, y era evidente utilidad de la Religión, Comendadores, y Cavalleros de la Castellanía de Emposta, se movió, hizo y acabó una permuta del dho. Lugar de Exatiell catorse casas con sus vasallos y quinse quiñones en el Lugar de Samper con el Lugar de Nonaspe y las Pinÿeres con authoridad de este Convento, contentamiento y voluntad de todos los de la Castellanía, nemine discrepante; de

47 ACA, Reial Audiència, Plets Civils, núm. 13170, fol. 32 r. 
tal manera que el Convento tomó por su Procurador la possessión pacífica de Nonaspe y las Piñeras ni más, ni menos el Sor. Castellán Villarregut la de Exatiell, catorse casas con sus vassallos, con sus quiñones, con authoridad y sello de una Bulla plumbea emanada de Nro. Sr. Illmo. Fr. Joan de Gomedes (sic), y de el Convento, la qual pacífica possessión de ambas partes duró hasta la muerte del dho. Sor. Castellán, que debieron passar hasta seis años de término ${ }^{48}$.

Però el traspàs de Pinyeres i Nonasp a la jurisdicció del Convent de Casp no va plaure al Castellà d'Amposta Joan Miquel del Castellar, que ocupà el càrrec entre 1560 i 1564, el qual pretengué desconèixer i anul lar l'esmentada permuta:

sucediendo después por Castellán de Emposta el Iltre. Sor. Dn. Joan Miguel del Castellar no solamente no quiso alterar la dha. permuta, pero ahun sacando una manutenencia de la Rl. Aud.' de Catt." se entregó de las Piñeras y su término, por estar dho. Lugar en el Reyno de Catt." lo que no pudo hazer ahunque lo tentó en el Lugar de Nonaspe por estar en Aragón, atento que visto el Convento haver tomado la possessión de Nonaspe, recurrió con la Bulla que del mismo Sor. Illmo. y de su Consejo tenía a la Aud. ${ }^{2}$ Rl. y por dha. Bulla les fue provehido ut tolli fortia con sus executoriales y dos Porteros Reales les fue restituhida dha. possessión que en Nonaspe tenía, y ansí mientras el dho. Sor. Castellán vivió, ni por los que después han sido no ha podido el Convento de Caspe gozar ni tener la pacífica possessión del término, y tierras de las Piñeras, ni es posible ${ }^{49}$.

El Convent de Casp, que havia vist també perjudicats els seus antics drets sobre Pinyeres per part del Castellà Lluís de Talavera, demanà al Capítol General de l'Hospital i al Gran Mestre de Rodes que per tots els mitjans legals retornessin els drets i la jurisdicció que li corresponia sobre Pinyeres i que mantenia sobre Nonasp en virtut de la permuta feta el segle XV amb Jatiel i tots altres béns i heretats de Samper de Calanda:

Por lo qual tan humildemente quanto puede Prior y Convento de Caspe suplican a V.S. Illma. Sacro y General Capítulo que sean servidos con Decreto particular y con penas para ello oportunas y necesarias, a más de confirmar dha. unión, mandar que libremente dexen los Señores Castellanos que son y por tiempo serán gosar de la Possessión del término y tierras de las Piñeras, pues es justo que gozando Exatiell, las catorze casas y vassallos y quinze quiñones los Sres. Comendadores de Samper, goze también el Convento de Caspe las Piñeras y su término, pues fue permutado, como dho. es ${ }^{30}$.

48 Ibidem, fol. $31 \mathrm{v}$.

49 Ibidem, fol. 31 r.v.

so Ibidem, fol. $31 \mathrm{r}$. 
El Gran Mestre i Capítol General de l'orde santjoanista confirmaren i novament atorgaren als santjoanistes de Casp la possessió, la jurisdicció alta i baixa i els drets censals que havien tingut i els corresponien sobre Pinyeres $\mathrm{i}$ Nonasp. Aquesta confirmació la feren amb butlla solemne datada a Malta durant la celebració del Capítol General el dia 24 de març de l'any 1574, signada per Fra Alonso de Solís, Gran Canceller, i per Fra Tomàs Gargallo, Vice-canceller, i bollada amb la Bulla nostra communis plumbea del Gran Mestre Levesque de la Calière:

qua propter meritorum suorum contemplatione suasi volentes ipsis facere gratiam spetialem invicem maturo et deliberato concilio, de nra. certa scientia, authoritate et decreto, ac in vim Generalis Capituli, praefatam permutationem et omnia et singula in supplicatione contenta thenore praesentium confirmamus, concedimus et donamus ea quae plenum sortire effectum conventumque ipsum Caspis in possessionem Loci de Nonaspe manuteneri decernimus, volumus et mandamus, praecipientes universis et singulis dictae domus nostrae Fratribus quacumque authoritate, dignitate officioque fungentibus, praesentibus et futuris in virtute Sanctae obedientiae, ne contra praesentes nostras literas aliquatenus facere vel venire praesumant, sed eas studeant inviolabiliter observare $"$.

El Gran Mestre i el Capítol General de l'orde, reunits a Malta durant el mes de març de 1574, comunicaren l'acord que havien pres sobre Pinyeres i Nonasp, favorable al convent de Casp, als comanadors de la Castellania d'Amposta:

Charissimis Fratribus Hieronimo Cornel de ombel (sic) ac pro nostro Concamerario in nra. Castellania Emposte Receptori Francisco Martínez de Marcilla de Alambra ac Sti. Joannis de Huesca, Francisco de Pomar de Villarluengo y la Cañada, Dionisio Coscón de Ulldecona, et Martino Garcés de Orta Commendarum nostrarum dictae Castellaniae Commendatariis ${ }^{52}$.

L'acord fou pres per unanimitat:

Rmus. Dnus. Magister et Rndum. Concilium Completum retentionum Capituli Generalis, habita relatione Comissariorum super id ad audiendum et referendum deputatorum, cum scrutinio ballotorum, nemine discrepante, confirmaverunt praefatam permutationem et decreverunt Conventum ipsum Caspis poni et restitui in possessione de les Piñeres, nec non manuteneri in possessione pacifica loci de Nonasp ${ }^{33}$.

"Ibidem, fol. 30 r.v.

s2 Ibidem, fol. 29 v.

"Ibidem, fol. 29 r. 
En passar els llocs de Pinyeres i Nonasp al domini dels santjoanistes de Casp, aquests hi exerciren la jurisdicció que els corresponia con a senyors -alta i baixa, mer i mixt imperi, civil i criminal; jurisdicció que no patí entrebanc fins el temps del Castellà d'Amposta Joan Miquel del Castellar, segons declaració de Joan Baptista Suñer, de Batea, un dels testimonis presentats a la Reial Audiència pel procurador del convent de Casp Mn. Miquel Bes, prevere, també de Batea:

(...) el testigo dixo (...) haver visto que el Prior y Convento de la Religión de Sn. Juan scito en la Villa de Caspe (...) como a Sor. Jurisdiccional del término de Piñeras de todo el tiempo de su acuerdo ha nombrado Bayle en el referido término, y ha visto por Bayles a Joseph Bes, Bautista Rams, Pedro Juan Bes y a Carlos Rams vezinos de Bathea que es la villa más cercana a dicho término, y a un tal Gamundí de la villa de Maella, dándoles su juramento el dicho Prior siendo éstos tenidos y reputados por tales Bayles (...) y haver assimismo ohido dezir a sus Mayores que dicho Prior y Convento de Religiosos han tenido toda la jurisdicción en dho. término, Civil y Criminal, y puesto y nombrado Bayles en dho. término, de conformidad que no ay memoria de hombres en contrario, sin contradicción de Persona alguna hasta el expressado año de 1753 y ser assí muy público y notorio en la pnte. Villa de Bathea y demás circumvezinas ${ }^{54}$.

La permuta de Pinyeres i Nonasp comportà també, com és lògic, el traspàs de gairebé tota la documentació referent a ambdós llocs de l'arxiu del castell de Miravet al del convent de Sant Joan de Casp. I és de l'arxiu d'aquest convent que el notari de Casp, Gabriel Chiprana, tragué còpia autèntica de la carta de poblament de Pinyeres, la còpia que estudiem:

Gabriel Chiprana Infanzón Esno. Real, Domiciliado en la Villa de Caspe de el Reyno de Aragón, Certifico que, en dha. Villa oy día de la fecha de el presente a Instancia y Petición de los Sres. Prior y Religiosos de el Combento de Sn. Juan de Jerusalén de la misma Villa, he pasado al mismo Combento y en él he sido conducido a su Archivo en el que habiendo tirado un Calaje notado en su Frontis -Piñeras- se ha sacado de él, y puesto en mi Mano una Escritura, y se me ha requirido diese Copia Auténtica y fee faciente de ella (segueix el trasllat íntegre de la carta de poblament de Pinyeres) cuya copia hize de dha. Escritura, a la letra et prout jacet, y habiéndola comprobado en la debida forma debolbí dha. Escritura original a Dhos. Sres. Prior y Religiosos para restituhirla a dho. Calaje o Cajón de donde ha sido sacada, y para que haga fee y conste donde combenga, a instancia y requerimiento de los mismos, doy signo y firmo el presente en la referida Villa a siete días de el mes de marzo de mil setecientos cinq. ${ }^{2}$ y ocho años $"$.

54 Ibidem, fol. 80 r.v.

ss Ibidem, fol. 35 v. -36 r.; 38 v. 
Actualment tota aquesta documentació del municipi de Pinyeres la guarda l'Arxiu Històric Nacional a la Secció d'Ordes Militars, Castellania d'Amposta, Batllia i Comanda de Casp: carpetes 605 i 606, caixes 8207 a 8223 i lligalls 236 a 253 .

\section{COMENTARI A LA CARTA DE POBLAMENT}

La còpia de la carta de poblament de Pinyeres existent a l'Arxiu de la Corona d'Aragó, feta pel notari de Casp, Gabriel Chiprana, ocupa els folis $36 \mathrm{r}$. a 38 v. del volum que inclou el plet civil posat davant la Reial Audiència de Catalunya pel prior i convent santjoanista de Casp contra el fiscal del civil de la Reial Audiència catalana. Aquest volum és signat amb el núm. 13.170 de la Secció de Plets Civils.

La carta de poblament fou atorgada pels frares del Temple com la resta de cartes de poblament i establiment agrari de la comarca de Gandesa. En aquest cas, l'atorgant és el Comanador de Miravet

frater Petrus de Tous Comendator Mirabeti, de mandatu et voluntate Dni. fratris Petri de Monte Cathano domus Militiae Templi in Aragonia et Catalonia Magistri,

el mateix que atorga les cartes d'Algars i Almudèfer. I ho fa amb el consell $\mathrm{i}$ consentiment de diversos frares del Temple:

fratris Eximenis de Lerida Comendatoris Cantevechiae, fratris Dalmatii de Sero Comendatoris Ambelli, fratris Guillelmi de Abelars Comendatoris Derthusae, fratris Guillelmi de Benages Comendatoris Ortae, fratris Guillelmi de Salecio Comendatoris de Ricla, fratris Raymundi de Villalba, fratris Raymundi de Sancto Danielo socii dicti Magistri, fratris Petri de Manresa Vicarii Miraveti, fratris Fernandi Rotundi fratris Capellani dicti Magistri et plurium aliorum fratrum nostrorum per nos et omnes successores nostros.

Els beneficiaris són cinc personatges, del quals ignorem l'origen, i llurs successors:

Damus et concedimus et in perpetuum tradimus vobis Berengario de Rocafort et Berengario de Montepalacio et Bernardo de Rocafort et Joanni de Montepalacio et Petro Fonoll et heredibus et successoribus vestris.

El «Memoriale instrumentorum quae erant in Miraveto», fet el 1308, 
l'única referència de la carta de Pinyeres que fins avui ens era coneguda, dóna tan solament el nom de dos dels beneficiaris, el de Berenguer de Rocafort i el d'Arnau de Montpalau. Cal dir que el nom d'aquest darrer no coincideix amb els de la còpia de la carta, puix que en aquesta no hi ha cap personatge anomenat Arnau. Aquesta referència fou inclosa per Font i Rius en el seu estudi sobre les cartes de poblament de Catalunya ":

Item, aliud instrumentum factum per comendatorem Miraveti super donationem et concessionem factas Berengario de Rochafort et Arnaldo de Monte Palacio et aliis quibusdam de manso vocato vulgariter Çes Pinyeres in termino de Algars. Et est dictum instrumentum per alphabetum divisum die et anno prescriptis, et clausum per dictum R. Sevina ${ }^{57}$.

L'objecte de poblament i donació és el mas de les Pinyeres amb tot el seu terme, inclòs dins el terme d'Algars, el límits del qual vénen especificats a la carta:

Damus et concedimus et in perpetuum tradimus vobis (...) et successoribus vestris nunc et in perpetuum ad populandum totum nostrum mansum vocatum vulgariter de les Piñieres, qui est in termino de Algás (...). Quae possessiones et honores et termini dicti Mansi afrontant ex una parte in rivo de Algás, et ex alia in camino de Fabara, et ex duabus partibus in Camino de Batea.

Aquest terme, que havia format una unitat territorial amb el terme d'Algars fins que les cartes de poblament corresponents els separaren donantlos entitat pròpia, és el que ha perdurat sense variacions a través dels segles fins a la seva incorporació al municipi de Batea, el 1841.

L'objectiu de la concessió per part del Temple de la carta de poblament fou doble: l'ocupació i el poblament del lloc-ad populandum, com ho expressa el text de la carta- $\mathrm{i}$ l'establiment agrari referent a les terres, per tal que aquestes fossin conreades bé i de manera continuada cum omnibus melioramentis quae ibi de caelo usque in abisum facere poteritis ullo modo. Val a dir que, per llur doble condició de pobladors i conreadors, els beneficiaris de la carta de Pinyeres estaven obligats a residir personalment i sense interrupció en el lloc que hom els donava, i això sota la pena de perdre béns i terres que el Comanador de Miravet podia donar a uns altres que hi anessin a residir. El text de l'instrument jurídic és clar:

s6 Josep M." FONT I RIUS, ob. cit., I, p. 504.

" ACA, Varia de Cancelleria, reg. 1, fol. 74 r.v. 
preterea volumus quod vos et vestri successores teneamini semper facere in dicto loco continuam residentiam personalem et ille vel illi qui non fecerint ibidem residentiam, ut est dictum, comendator Miraveti, qui pro tempore esset, possit possessiones et honores quas ipsi ibi haberent et tenerent aliis hominibus ibidem volentibus residentiam facere dare et concedere et etiam asignare pro libito voluntatis.

Els drets del pobladors dins el terme repoblat els especifica la carta tot referint explícitament els diversos tipus de béns naturals i artificials que aleshores hi havia o en el futur hi podria haver:

cum domibus, casalibus, vineis, hortis, hortalibus, terris cultis et incultis, cum arboribus fructiferis et infructiferis, cum lignis, petris, aquis, pratis, pascuis et venationibus ac piscationibus, nec non cum omnibus aliis quae ibi sunt et ad usum hominis pertinere noscuntur.

Aquests drets inclouen, evidentment, tots els altres drets concomitants a qualsevol propietat o possessió, com els drets d'entrada i eixida, el millorament dels béns atorgats i llur plena i efectiva possessió sense cap mena d'ingerència i entrebanc del senyor jurisdiccional:

ipsos honores et possessiones damus et concedimus vobis et heredibus et successoribus vestris cum ingressibus et egressibus suis et cum iuribus et pertinentiis suis et cum omnibus melioramentis quae ibi de caelo usque in abisum facere poteritis ullo modo et cum omnibus superius comprehensis et aliis pertinentibus vel pertinere debentibus ad dictum Mansum quae dici vel nominari vel excogitari possint aliqua ratione hic expresis et non expresis, et in plenam et corporalem possessionem vos introducimus et mittimus de predictis cum hoc instrumento pleno jure, et tenere et possidere plenius et firmiter pace et quiete vobis et vestris successoribus sine forcia seu violencia Domini terrae perpetuo faciemus.

Però tots aquests drets no són atorgats als pobladors nude et simpliciter sinó amb pactes i sota condicions. La primera condició, ja comentada abans, va estretament lligada al caràcter de poblament i d'establiment agrari que té la carta. I aquesta condició és doble: fixar de manera estable i continuada la residència personal dins el terme de Pinyeres i ser fidel al compromís de treballar les terres, augmentar-ne els conreus i mantenir-los productius com més millor. No cal dir que el millorament de les terres i l'extensió dels conreus afavorien les condicions del terme, els interessos del senyor i la situació econòmica dels vassalls. Un terme ric i productiu sempre era bo per a tothom. El senyor rebia més en concepte de delmes, censos i altres tributs, com la primícia, els drets de forn i de molins. Els vassalls també milloraven les seves 
condicions de vida si les collites eren més abundoses i bones. I el lloc en sortia beneficiat per totes dues bandes.

La segona condició és de caràcter econòmic i també doble: com a bons vassalls han de satisfer al comanador, als frares i a llurs successors i al castell de Miravet el delme i la primícia segons el costum de Batea. Delme i primícia que s'havien de repartir entre els templers i el bisbe de Tortosa. I, a més, han de pagar al Temple de Miravet un cafís de cereal -mig de blat i mig més d'ordiper cada parellada de terra conreada.

El pagament del delme i de la primícia es dividia entre el bisbe de Tortosa i els templers segons les clàusules d'un document de composició i concòrdia fet expressament entre els frares de Miravet i el bisbe sobre el delme i la primícia d'Algars, al terme del qual havia pertangut Pinyeres:

Hanc autem concesionem et donationem vobis facimus sub istis pactis et conditionibus quod vos et vestri successores detis nobis et successoribus nostris et castro Miraveti decimam et primitiam secundum consuetudines in quibus sunt homines de Batea populati; quae quidem decima et primitia dividatur inter nos et Episcopum Derthusensem prout in instrumento compositionis factae super decima et primitia de Algás inter Templum et eundem Episcopum continetur.

Les clàusules de la concòrdia d'Algars, que ens és fins ara desconeguda, devien coincidir amb les de la concòrdia feta i signada el 27 de maig del 1185 entre Ponç de Mulnells, bisbe, amb el consentiment del prior i capítol de la Seu de Tortosa, i fra Ramon de Canet, mestre de la Milícia del Temple de Salomó.

Aquesta concòrdia fou feta sobre els delmes i les primícies del castell $\mathrm{i}$ terme d'Orta i sobre totes les colonitzacions i poblaments que els templers poguessin fer en temps a venir dins els límits del bisbat de Tortosa, inclosos també els termes d'Ascó i Riba-roja i exceptuats tan solament el terme i la ciutat de Tortosa. Els drets que feia valer el bisbe eren drets que posseïa per concessió o confirmació de Ramon Berenguer IV i d'Alfons el Cast, un cop reconquerida la ciutat de l'Ebre als àrabs, si bé alguns drets els tenia ja des de l'època visigòtica. Als drets esmentats fa referència Alfons I en la carta de poblament de Batea i d'Algars quan cedeix al notari reial Berenguer de Parets les esglésies que s'arribessin a construir durant el temps de la seva vida salvo iure Dertusensis episcopi. Atès que el poblament de l'Algars fou fet posteriorment a la concòrdia esmentada i el terme i lloc d'Algars eren situats dins el bisbat de Tortosa, deduïm que les clàusules d'aquesta concòrdia degueren coincidir amb les de la primera. Deducció que ve a confirmar-nos la composició feta entre el bisbe de Tortosa, els de Gandesa i els de Batea sobre la manera de delmar, signada el 9 de juliol del $1268^{s 8}$.

s8 AHN, OO. MM. Sant Joan de Jerusalem, Castellania d'Amposta, Batllia de Miravet, carpeta 609, núm. 46, ligamen 6, núm. 7. 


\section{Segons aquesta concòrdia d'Orta, establerta}

ad pacem et firmam concordiam perpetuo conservandam inter nos et venerabiles fratres Milicie Templi Salomonis, el bisbe donava al Temple tertiam partem omnium decimarum castelli de Orta et de omnibus terminis suis, tali scilicet modo quod bajulus noster insimul cum bajulo vestro fideliter decimas istas congregent in locis competentibus, de quibus nos habeamus duas partes et vos tertiam partem, et quod populatores loci illius donent nobis et clericis nostris ibi constitutis primitiam fideliter omnium fructuum et animalium, scilicet trigesimam partem omnium rerum, de quibus decimam dederint vestrecumque vero ecclesie parochiali dabitis per dominicaturam libere et ingenue, sine censu et usatico ullo, unam kafiçadam terre in loco competenti cementerii et loca ad ecclesiam construendam et ad construendas domos clericorum. Retinemus autem nobis ecclesias omnes in iamdicto loco constructas (...) et omnia alia que ad ius episcopale pertinere noscuntur (...), Preterea ego Pontius, Dertusensis episcopus, Pontius prior et alii canonici damus et concedimus vobis Raymundo de Caneto Magistro iam dicto, aliisque fratribus vestris Milicie in omnibus populationibus que, Deo volente, in episcopatu nostro populaveritis ac populatas adquirere poteritis, vel quondam adquisistis, excepto Dertuse et termino suo (...) tertiam partem omnium decimarum, et quod nos habeamus duas partes, sub tali conditione quod vos nobis faciatis dare fideliter primitias omnium rerum, scilicet ad trigesimam partem, ut dictum est de Orta, et quod retinuerimus nobis omnes ecclesias et clericos et oblationes et defunctiones et omnia alia que ad iura episcopalia pertinent ${ }^{5 \%}$.

El delme i la primícia s'havien de satisfer segons el costum de Batea, costum que regia també el pagament d'aquests drets per als pobladors d'Algars i de la Pobla de Massaluca. Segons el costum de Batea, hom pagava de delme

be e fidelment de tot blat la docena garba dins el camp, levada la tascha tant solament, e quan auran seguat el camp ans que traguen los dits homens blat del camp quel senyor del blat ho son missatger deguen e facen saber a la hu dels batlles sie esperat alí a delmar per una nuyt ho per migdia (...) Item donen e paguen be e fidelment de raim e verema la docena part dins la vinya veremada, e de cols, de porros, de ayls, e de li, de canem, de naps la deena part dins en lort e de totes legums la deena mesura levada en la era, e de farratge aximetex la deena, que no la hauran

5) ACA, OO. MM. Sant Joan de Jerusalem, Gran Priorat de Catalunya, secció II, armari de Tortosa, núm. 4, vol. 3, fol. 43 r., doc. 135. Hom pot trobar transcripció del document i estudi del tema a La Comanda del Temple de Tortosa de Laureà PAGAROLAS, pp. 134-139; 265-267. 
donada ha besties darada. Fo eix tracte ordenat e feyt entre les parts quels dits homens donen la deena part danyels e de cabrits en la festa de Çinquagesima, e no sien tenguts dar delma ho primiçia de lana ni de formatges. E com sien tenguts dar I porçel una vegada en lan per quada una truya, axi empero si aquela truya avia porçel aquel an aquest porçel donen per delme e per promiçia a cap de III setmanes. E quescun galliner sie tengut dar en lan I pol de galiners. Encara fo feyt e ordenat entre les parts que de la flo de safra donen la XII ${ }^{\star}$ part. de olives la XIII ${ }^{a}$ mesura ho axi com se fara en Orta ${ }^{(n)}$.

Una altra condició econòmica que els pobladors de Pinyeres havien de complir envers els templers de Miravet era el pagament en espècie d'un cafís de cereal -mig de blat i mig més ordi- per cada parellada de terra. Aquest cens l'havien de satisfer una vegada cada any per la festa de Sant Miquel de setembre (29 de setembre), dia que ha esdevingut la data de la festa major de Batea. La carta especifica que el valor de la parellada concedit als de Pinyeres era el mateix que el de la vila de Batea; valor també concedit als pobladors d'Algars i als de la Pobla de Massaluca, que coincideix amb el de les altres viles i llocs de la comarca, excepció feta de Vilalba, les Camposines i Orta; («donamus et in perpetuum concedimus populatoribus Bathee presentibus et futuris eorumque successoribus pariliatam terre de XXIIII kafizadas») ${ }^{61}$. La parellada (de parell) era una mesura de superfície agrària, també anomenada «bovada» i «jovada» (de bou i jou respectivament), que venia a equivaler a l'extensió de terra que podia llaurar un parell de bous en un dia. Aquesta extensió corresponia a unes 25 o 30 àrees:

Preterea quod vos et successores vestri detis nobis et successoribus nostris et castro Miraveti pro unaquaque pareliata, secundum quod ibi fuerint pareliate, unum caficium bladii medium ordei et medium frumenti annuatim in festo Sancti Michaelis septembris, que quidem pareliata est XXIIII caficatarum secundum formam quod Villa de Batea extitit populata.

La carta de Pinyeres inclou, a més, un conjunt de retencions o reserves senyorials, derivades del vincle feudal que lligava els pobladors com a vassalls amb llur senyor. Reserves que també trobem a les cartes de poblament i establiment agrari d'Algars, Batea, la Vall de Batea, Gandesa, el Pinell, Vilalba i la Pobla de Massaluca. Drets senyorials que aparegueren expressats

${ }^{60}$ AHN, OO. MM. Sant Joan de Jerusalem, Castellania d'Amposta, Batllia de Miravet, carpeta 609, núm. 46, ligamen 6, núm. 7.

${ }^{6}$ AHN, OO. MM. Sant Joan de Jerusalem, Castellania d'Amposta, Batllia de Miravet, carpeta 309, ligamen 7 , núm. 4. 
per primer cop a la comarca en el text de la carta d'Orta del 1192. La carta els enumera detalladament tot al-ludint després a qualssevulla altres drets que puguin correspondre a la senyoria sobre els seus vassalls, que són els mateixos que té i exerceix sobre els habitants de Batea.

Retinemus insuper nobis et successoribus nostris et Castro Miraveti ibi locedum, furnos, molendinos, carnicerias, fabricas, firmamenta secundum consuetudines de Batea, et calonias, dominia et omnia jura atque res alias quascumque dominationes quas habemus vel habere debemus in hominibus de Batea.

El primer dret senyorial reservat és el dret de llòssol o dret de llossi (locedum), que era un cens que percebien els senyors dels seus vassalls pel servei d'esmolar a les ferreries les arades, relles, dalles, destrals i totes altres eines de tall, i també pel servei de ferrar-hi les cavalleries. El nombre d'animals de treball que tenia cada casa decidia la quantia del llòssol. Així consta en el Memorial de los derechos, regalias, preminencias, fincas, posesiones, rentas, fueros y demás pertenencias tocantes a esta Encomienda de Batea, que el doctor Pere Joaquim Alcorisa, advocat dels Reials Consells i Procurador Jurisdiccional del Molt Iltre. Sr. Fra Nicolàs de Texedor, Comanador de Batea, presentà als comanadors Joan Baptista Vallés i Jaume Borràs que acudiren a la vila per fer visita de milloraments de la Comanda de Batea:

tiene asimismo dho. Comendador el derecho llamado comunmente de llosi que consiste en que cada Labrador que tiene un par o más de cavallerías deve contribuirle anualmente con tres quarteles de trigo y otros tantos de cevada, y los que tienen bueyes o solo medio par de mulas pagan por metad este derecho ${ }^{62}$.

El capbreu de Batea i d'Algars de l'any 1781 recull també aquest dret, indicant-ne la data de pagament:

se le paga al Comendador por la fiesta de San Miguel de Septiembre el derecho llamado de LLosi, esto es diez almudes de Trigo, y diez de Zebada por cada casa que tiene dos animales de trabajo o más. Y los vezinos que no tienen sino una Bestia no pagan más que la mitad, esto es cinco almudes de Trigo, y cinco de Zebada ${ }^{63}$.

${ }^{62}$ AHN, OO. MM, Sant Joan de Jerusalem, Castellania d'Amposta, caixa 8265, lligall 314 , núm. 32 , fols. 5 v. -6 r.

${ }_{63}$ Antonio MASCARÓ, Mis Memorias, Barcelona, 1948, Imprenta y Editorial Altés, s.l., pp. 50-51. Hi ha el text i comentari del «Cabreo de Batea y Algás, Quarta Encomienda de las erigidas y formadas en la Baylía de Mirabete en virtud del Decreto de Desmembración de las Rentas de la Dignidad del Gran Castellán, en el año 1781 ", lligall guardat a Casa Català de Batea. 
Un altre dret reservat és el d'establir forns de destret als quals els vassalls venien obligats a coure el pa (furnos). Com a propietat del senyor que eren, aquest prenia solemne possessió dels forns i en rebia el dret de fornatge. El 31 d'agost del 1576 fra Joan Cortés, després d'haver pres possessió del castell de Pinyeres, va baixar al forn i va ficar-hi un pa que, tot seguit, extragué in signum verae et realis possessionis.

Els altres drets fan referència als molins, a les carniceries, a les ferreries, als beneficis derivats de l'exercici de la justícia i de l'establiment dels tribunals del senyor, drets que el senyor es reserva segons els costums de Batea i que, per tant, els vassalls han de respectar $\mathrm{i}$ complir escrupolosament com ho fan els homes de Batea. Aquests drets senyorials van lligats a la doble jurisdicció civil i criminal, constatada i reconeguda pels vassalls de Pinyeres i pels habitants del pobles veïns. Així ho manifesta Jeroni Balaguer, llaurador de Batea, de 70 anys, que indica la conformitat dels drets del senyor a Pinyeres amb els de Batea com a prova que s'observaven els costums de la vila en tot el terme del llogaret proper:

el Prior y Convento de Caspe han nombrado y juramentado Bayles en el dho. término a muchas personas terratenientes de la presente villa y de las villas de Maella y Calaceite (...) y haver visto exercer la Jurisdicción Civil y condenar los Bayles nombrados por dho. Prior y Convento a las penas de coger piñas y executar en todo y por todo lo concerniente a la administración de justicia si y en la misma conformidad lo hace en la presente villa el Bayle de ella, y assimismo ha visto exercer la jurisdicción criminal pues en el año dos o tres cogió el Bayle del dho. término de Piñeras una partida de gitanos que robaron en aquel término de Piñeras y los puso en aquella cárcel... ${ }^{64}$.

Aquest dret senyorial de conèixer causes civils i criminals, dictar sentències $i$ aplicar les penes conformes a dret i costum el confirma Josep Peig, de 83 anys, també llaurador de Batea, un altre dels testimonis aportats pels santjoanistes de Casp davant la Reial Audiència de Catalunya:

Dixo que (...) de todo el tiempo de su acuerdo que le tiene de más de setenta años y haverlo ohido dezir a sus mayores y antipassados que siempre que ha venido el caso de formar procesos y de exercer jurisdicción y administrarse justicia en el término de las Piñeras scito en el Principado de Cataluña se ha executado y practicado en nombre o del Prior y Convento de la Religión de Sn. Juan de Caspe del Reyno de Aragón, o del Bayle o Bayles por dicho Convento elegidos y nombrados haverlo visto siempre assí observar en dha. conformidad de todo el tiempo de su acuerdo

64 ACA, Reial Audiència, Plets Civils, núm. 13170, fol. 64 v. 
(...) de forma que hallándose el testigo criado rabadán en el dho. término de Piñeras con Gabriel Gamundí de Maella entonces habitante allí al tiempo que habitava en dho. término de Piñeras un hombre aragonés llamado Joseph Días el que quería casarse con una viuda llamada Montaguda la qual tenía dos hijos, llamado el uno Rafael, que no querían consentir en el casamiento, en la Plaza de dho. término tiró este al dho. Joseph una escopetada y le mató y luego huyó y al mesmo tiempo vio el testigo fueron luego el Assessor y el Bayle de dho. término de Piñeras elegido, nombrado y juramentado por el dho. Prior de San Juan de Caspe, el Escribano y el nuncio haziendo seremonias de visurar y llamar el muerto, que los nombres no se le acuerdan y formaron su processo criminal por el dho. Bayle de orden del dho. Prior y Convento, lo que es muy público y notorio en la presente Villa de Bathea ${ }^{69}$.

A cada poblador hom li imposa un cens simbòlic, que també trobem a la carta de poblament d'Algars, pel solar de les cases, consistent en una gallina de cens a donar per la festa del Nadal de Nostre Senyor (el 25 de desembre), cens que per privilegi no obliga tres dels pobladors $\mathrm{i}$ els seus hereus i succesors: Berenguer de Rocafort, Joan de Montpalau i Pere Fonoll:

Et quilibet populator dicti loci donet nobis et successoribus nostris et castro Miraveti pro salario domorum unam gallinam censualem in festo Natalis Domini annuatim, exceptis Berengario de Rocafort et Joanne de Monte Palazio et Petro Fonol praedictis qui pro salariis domorum nullum teneantur facere censum neque successores eorumdem ${ }^{66}$.

No estranya gens que en tractar-se d'una carta de poblament que, a més, dóna a poblar un indret allunyat del castell de Miravet i situat en terra fronterera, els templers exigeixin als pobladors que hi estableixin llur residència personal de manera continuada sots pena de perdre totes les heretats $i$ els drets atorgats. Això vol dir que no era suficient el compromís verbal de residència per part dels pobladors; els calia lligar llur vida i familia a Pinyeres amb l'assentament exigit.

Atesa també la importància que tingué durant els segles XII i XIII la ramaderia, tant de bestiar gros com menut, sobretot per a l'Orde del Temple per tota la batllia de Miravet, entenem les reserves que explicita la carta de Pinyeres, com ho fan també la d'Algars i la resta de cartes comarcals, pel que mira a les pastures i terres de devesa. Els ramats eren riquesa de carn, de cuir i pells per a pergamí i bóts, de llet i formatges i també de llana. I, tractant-se del bestiar gros, no cal dir la importància que tenia la cria de les bèsties de treball

6s Ibidem, fol. 46 r.

${ }^{66}$ Ibidem, fol. 37 rv. 
-cavalls, muls, ases i bous- per a transformar el camp en terres de conreu. La gran extensió de les terres de pastura per tota la comarca afavoria una florent ramaderia. Fet que confirmen les grans deveses templeres de Berrús, el Massalocà, els Ports d'Orta i la de les serres de Pàndols i Cavalls. Els atorgants de la carta es reserven els prats $i$ les pastures per als ramats del castell de Miravet i prohibeixen als pobladors fer-ne tala si no és que la paguin.

Volumus etiam et retinemus nobis et successoribus nostris pascua ad bestiarium grossum et minutum proprium domus Miraveti sine tala, quam si fecerint, solvant eam ${ }^{67}$.

La carta inclou unes altres reserves dominicals referents a la fusta i als pinars, en aquest cas adaptades a la condició concreta del terme de Pinyeres que era aleshores, amb el d'Algars, un indret força poblat de pi blanc i de pi pinyoner. Els pobladors poden tallar els pins que necessitin per a fer-ne jous, bigues i travessers per a llurs cases i masos i, també, altres objectes de fusta d'ús domèstic i agrícola. No tenen autorització, però, per a fer-ne un negoci venent troncs o fusta tallada als estranys ni tampoc per a fer-los-en gratuïta donació. I la raó d'aquesta limitació sembla ésser la previsible necessitat de fusta per als projectes de construcció que tenien els templers i la voluntat ferma de no degradar $\mathrm{i}$ empobrir els boscos $\mathrm{i}$ arbredes amb una tala excessiva. Per això, els atorgants de la carta es retenen tots els drets sobre la fusta per a ús exclusiu de les cases del Temple de la batllia de Miravet, amb l'excepció només de l'ús ordinari dels pobladors, ja expressat.

Et quod vos neque successores vestri non possitis alicui persone extranee fustam de pinis dare vel vendere, videlicet cabironos, bigas vel travesarios, sed habeatis vos et vestri successores dictam fustam ad vestrum proprium usum. Retinemus tamen nobis et successoribus nostris fustam in dicto loco ad usum similiter domorum Templi bajuliae Miraveti ${ }^{68}$.

Una altra reserva senyorial -aquesta ben curiosa i estretament lligada al topònim del lloc- és la referent als pins pinyoners o pinyeres i a llurs fruits, les pinyes. A l'indret $n$ 'hi devia haver molts ja de temps immemorial i donaren denominació al mas i al terme: «les Pinyeres» o simplement «Pinyeres», les dues formes que hem trobat en els documents des del segle XIII fins al XVIII. Tres pinyes sobremuntades per una creu potençada són les figures que ocupen

67 Ibidem, fol. $37 \mathrm{r}$.

${ }^{68}$ Ibidem, fol. $37 \mathrm{r}$. 
el camp heràldic del segell de la cúria i batlle de Pinyeres, emprat durant el segle XVI; segell empremtat en sec sobre cera vermella i hòstia de paper ${ }^{69}$.

Els pins pinyoners (Pinos Donzeles) eren gairebé sagrats per als pobladors, que no podien tallar-ne, destruir-ne ni transplantar-ne cap sense permís explícit del comanador de Miravet i, més tard, del prior del convent santjoanista de Casp. I de les pinyes i pinyons només podien quedar-se amb una tercera part, ja que les altres dues eren reserva dominical en virtut del text de la carta de poblament. Els pinyons, amb les nous, ametlles, avellanes, figues seques $i$ panses, eren molt estimats com a fruita seca en l'alimentació medieval. La tasca laboriosa de trencar i destriar els pinyons explica que la recollida de pinyes $\mathrm{i}$ l'extracció i neteja dels pinyons fossin imposades com a pena als delinqüents pel batlle del lloc. Així ho fa constar Jeroni Balaguer, llaurador de Batea: «Dixo (...) haver visto exercer la Jurisdicción Civil y condenar los Bayles nombrados por dicho Prior y Convento (de Caspe) a las penas de coger piñas" "0. El text del document poblacional és ben explícit i detallat:

Preterea retinemus nobis et succesoribus nostris et castro Miraveti perpetuo omnes pinos donzeles qui sunt vel deinceps fuerint in termino dicti Mansi, ita quod ipsos pinos vel aliquem ex ipsis absque voluntate Comendatoris Miraveti nunquam possitis scindere vel destruere vel eos inde amovere, et habeamus nos et successores nostri semper duas partes fructuum eorundem et vos et vestri tertiam partem.

Els pobladors de Pinyeres, com els d'Algars i de molts altres llocs i viles de la comarca, reben dels templers autorització per a vendre i posar en altres mans les heretats que s'han compromès a treballar bé i segons les seves possibilitats; tanmateix, vénen obligats en virtut de la carta de poblament a donar al Temple de Miravet deu dies de fadiga, que és el termini del costum de Batea. Abans de finir els deu dies, comptadors des del moment de la notificació de la voluntat de vendre o d'alienar, els templers poden quedar-se l'heretat alienable tot pagant al venedor el mateix preu ofert pel comprador. Un cop acabat el termini i no havent exercit el senyor el dret de fadiga, s'entén que hom pot fer la venda amb plena llibertat a qualsevulla dels altres pobladors del mateix lloc de Pinyeres, mai, però, als eclesiàstics ni als cavallers.

Item volumus quod vos et succesores vestri laboretis bene et fideliter dictas

${ }^{69}$ ACA, Reial Audiència, Plets Civils, núm. 7655, fol. 192 r. Aquest segell, que Ferran de Sagarra no recollí dins la seva Sigil lografia catalana, ha estat publicat per primera vegada per Josep AlanYà I RoIG a El terme municipal: Pinyeres, «La Vila Closa» (1990), núm. 16, p. 190.

${ }^{70}$ ACA, Reial Audiència, Plets Civils, núm. 13170, fol. 64 v. 
possessiones et honores vestro posse, et si forte vos vel successores vestri dictas possessiones vel honores vel partem ipsarum vendere vel alienare volueritis, quod detis fatigam nobis dezem dierum secundum Consuetudinem de Batea, et quod possideamus eas si voluerimus pro pretio vobis oblato libere retinere, quas, nisi retinere voluerimus, possitis eas vendere vel alienare vestris consimilibus habitatoribus in dicto loco, exceptis militibus atque sanctis, quibus dare seu vendere ac alienare aliquatenus non possitis.

A la carta s'expressa també el preu que han pagat els pobladors al Temple de Miravet per la concessió i donació que els ha fet del Mas de les Pinyeres amb el seu terme: 700 sous de moneda jaquesa, que els templers ja han cobrat $i$ amb els quals ja es donen per ben pagats. Aquesta quantitat pecuniària, pagada "pro introitu», vertadera compensació monetària a la donació del lloc, revela un cert aspecte negocial en la concessió de Pinyeres, aspecte que no trobem en cap més carta de poblament de la Terra Alta. Buscant una explicació a aquest fet, pensem que aquest pagament pecuniari per part dels pobladors, en concepte d'entrada efectiva en possessió del lloc de Pinyeres, podria respondre a la causa originària de l'atorgament de la carta que més aviat devia ser a iniciativa i petició dels pobladors que no pas a iniciativa dels templers.

Pro qua autem donatione et concessione confitemur et recognoscimus habuisse et recepisse a vobis pro introitu DCC solidos jaccen. de quibus per pacatos nos tenemus, renuntiantes exceptioni pecuniae non traditae vel receptae et doli.

La carta acaba amb l'expressa acceptació de les condicions de l'establiment agrari per part dels beneficiaris i el compromís formal de complir-les com a fidels vassalls de l'Orde del Temple. Aquest compromís és la resposta dels pobladors a la voluntat expressada en el mateix document per part dels atorgants que exigeixen del pobladors lleialtat, fidelitat i vassallatge feudal, alhora que els garanteixen defensa, protecció $i$ bon tracte com a terratinents lliures que són-bomines proprii.

Volumus etiam quod vos et vestri successores teneamini et sitis homines et vassalli proprii et fideles ac legales Templi. És l'exigència dels templers. Nos vero populatores predicti per nos et omnes successores nostros vobis promittimus et successoribus vestris et fratribus supradictis ac etiam Templo esse homines et vassalli fideles ac legales vestri et successorum vestrorum et etiam Templi.

Prometen, a més, al Temple $\mathrm{i}$ als frares del castell de Miravet de satisfer cada any el cens, el delme i la primícia fidelment i lleial de totes les honors i heretats segons el costum de Batea, pagant així de cens un cafís de cereal per 
cada parellada, mig de blat i l'altre mig d'ordi, el dia de la festa de Sant Miquel del mes de setembre. Assumeixen també els pobladors, amb voluntat formal de complir-ho, totes les condicions i els pactes expressats a la carta: et omnes alias quascumque conditiones et pacta superius comprehensa tenere et observare inviolabiliter et complere, et nunquam contravenire aliqua ratione.

La carta, molt semblant en contingut i en forma a la d'Algars, és feta el dia 8 de setembre de 1280 sense indicació del lloc, característica comuna de totes les cartes de poblament i establiment agrari atorgades pels templers de Miravet dins la comarca de Gandesa. Segueixen a la data les signatures de fra Pere de Montcada, "domorum Militiae Templi in Aragonia et Catalonia Magistri ac tenentis locum Magistri Ultramarini in tota Hispania», de fra Pere de Tous, comanador de Miravet, i dels altres comanadors amb el consell i consentiment dels quals ha estat atorgada la carta, els noms i càrrecs dels quals ja figuren al començament de l'instrument jurídic.

Acompanyen les signatures dels templers esmentats, qui haec omnia et singula laudamus, concedimus et firmamus, les signatures dels testimonis i del notari que escriu i tanca la carta, Ramon Savina, el mateix de la carta d'Algars, de la d'Almudèfer i de la carta de la Pobla de Massaluca:

Sig+num Bernardi de Regali, bajuli Ortae. Sig+num Petri Salvatoris de Regali. Sig+num Vitalis Sabaterii, habitatoris de Batea. Sig+num Raymundi Savine, notarii jurati Domini Magistri et praedictorum fratrum scripsit et clausit die et anno praedictis.

La carta de Pinyeres, amb la de l'Algars, la d'Almudèfer i la de la Pobla de Massaluca, fou de les darreres cartes atorgades pel Temple a la comarca de la Terra Alta. La seva concessió comportà la divisió de l'antic terme i devesa del Riu d'Algars, repoblat per la carta d'Alfons el Cast l'any 1181.

\author{
JOSEP ALANYÀ I ROIG \\ Institut de Batxillerat "Infanta Isabel d'Aragó» \\ (Barcelona)
}




\section{APÈNDIX DOCUMENTAL}

1280, setembre, 8 .

Carta de poblament atorgada per fra Pere de Tous, comanador de Miravet, a Berenguer de Rocafort, Berenguer de Montpalau, Bernat de Rocafort, Joan de Montpalau $i$ Pere de Fonoll. Els fa donació del mas i terme de les Pinyeres, situats al terme d'Algars, $i$ dels aprofitaments comunals, amb l'encàrrec d'establir-bi continuada residència personal. S'estableixen les condicions tributàries segons el costum de Batea. L'Orde del Temple es reserva diversos drets $i$ béns, entre els quals cal destacar el dret sobre els pins pinyoners $i$ llurs fruits.

(A). Original, actualment perdut. Existent a l'Arxiu de Miravet en 1308.

B. Còpia de (A) (?) del 7 de març de 1758, realitzada pel notari reial de Casp Gabriel Chiprana, inclosa dins el volum del plet posat pel Prior i Convent de Sant Joan de Casp contra el Fiscal de Sa Majestat en les causes civils de la Reial Audiència de Catalunya.

Arxiu de la Corona d'Aragó, Reial Audiencia, Plets Civils, plet núm. 13.170, fols. 35 v. al 38 v.

In Nomine Sanctae et individuae Trinitatis, Patris et Filii et Spiritus Santi Amen: Sit omnibus manifestum quod nos f. Petrus de Tous Comendator Miraveti, de mandatu et voluntate Dni.f. Petris de Monte Cathano, domus Militiae Templi in Aragonia, et Catalonia Magister, ac tenentis locum Magistri Ultramarini in tota Hispania et de consilio et asensu f. Eximenis de Lerida Comendatoris Cantevechiae, f. Dalmatii de Sero Comendatoris Ambelli. f. Guillelmi de Abelars, Comendatoris Derthusae. f. Guillelmi de Benages Comendatoris Ortae, f. Guillelmi de Salecio Comendatoris de Ricla, f. Raymundi de Villalba, f. Raymundi de Sancto Danielo, socii dicti Magistri, f. Petri de Manrresa, vicarii Miraveti, f. Fernandi Rotundi fratris Capelani dicti Magistri et plurii aliorum fratri nostrorum per nos et omnes successores nostros, cum hoc instrumento firmiter et perpetuo valituro scienter et consulte et ex certa scientia damus et concedimus et in perpetuum tradimus vobis Berengario de Rocafort et Berengario de Monte Palazio et Bernardo de Rocafort et Joanni de Monte Palacio et Petro Fonol et heredibus, et successoribus vestris nunc et in perpetuum ad populandum totum nostrum Mansum vocatum vulgariter de les Piñieres qui est in termino de Algas, cum domibus, casalibus, vineis, hortis, hortalibus, terris cultis et incultis, cum arboribus fructiferis et infructiferis, cum lignis, petris, aquis, pratis, pasquis et venationibus ac piscationibus, nec non cum omnibus aliis quae ibi sunt et ad usum hominis pertinere noscuntur. Quae posesiones et honores et termini dicti Mansi afrontant ex una parte in Rivo de Algas, et ex 
alia in camino de Fabara, et ex duabus partibus in camino de Batea sunt honores et posesiones dicti Mansi in his affrontationibus includuntur et terminantur, et nos hodie tenemus et posidemus sic ipsos honores et possessiones damus et concedimus vobis et heredibus et successoribus vestris cum ingresibus et egresibus suis et cum juribus et pertinentiis suis et cum omnibus melioramentis quae ibi de caelo usque in abisum facere poteritis ullo modo et cum umnibus superius comprehensis et aliis pertinentibus vel pertinere debentibus ad dictum Mansum quae dici vel nominari vel excogitari possint aliqua ratione hic expressis et non expressis, et in plenam et corporalem possessionem vos introducimus et mittimus de predictis cum hoc instrumento pleno jure, et tenere et possidere plenius et firmiter in pace et quiete vobis et vestris successoribus sine forcia seu violencia domini terrae perpetuo faciemus. Hanc autem concesionem et donationem vobis facimus sub istis pactis et conditionibus: quod vos et vestri successores detis nobis et successoribus nostris et castro Miraveti decimam et primitiam secundum consuetudines in quibus sunt homines de Batea populati, quae quidem decima et primitia dividatur inter nos et Episcopum Derthusensem prout in instrumento compositionis factae super decima et primitia de Algas inter Templum et eundem Episcopum continetur. Preterea quod vos et successores vestri detis nobis et successoribus nostris et castro Miraveti pro unaquaque pareliata secundum quod ibi fuerint pareliate unum caficium bladii, medium ordei et medium frumenti annuatim in festo Sancti Micaelis septembris, quae quidem pareliata est XXIIII caficatarum secundum formam quod villa de Batea extitit populata. Retinemus insuper nobis et successoribus nostris et castro Miraveti ibi locedum, furnos, molendinos, carnicerias, fabricas, firmamenta, secundum consuetudines de Batea, et calonias, dominia et omnia jura atque res alias quascumque dominationes quas habemus vel habere debemus in hominibus de Batea. Et quilibet populator dicti loci donet nobis et successoribus nostris et castro Miraveti pro solario domorum unam gallinam censualem in festo Natalis Domini annuatim, exceptis Berengario de Rocafot et Joanne de Monte Palazio et Petro Fonol praedicti qui pro suis solariis domorum nullum teneantur facere censum neque successores eorumdem. Volumus etiam quod vos et vestri successores teneamini et sitis homines et vassalli proprii et fideles ac legales Templi. Preterea volumus quod vos et vestri successores teneamini semper facere in dicto loco continuam residentiam personalem, et ille vel illi qui non fecerint ibidem residentiam ut est dictum, Comendator Miraveti qui pro tempore esset possit possessiones et honores omnes, quas ipsi ibi haberent et tenerent, aliis hominibus ibidem volentibus residentiam facere dare et concedere et etiam asignare pro libito voluntatis. Volumus etiam et retinemus nobis et successoribus nostris pascua ad bestiarium grosum et minutum proprium domus Miraveti sine tala quam, si fecerint, solvant eam. Et quod vos neque successores vestri non possitis alicui personae extraneae fustam de pinis dare vel vendere, videlicet cabironos, bigas vel travesarios, sed habeatis vos et vestri successores dictam fustam ad vestrum proprium usum. Retinemus tamen nobis et successoribus nostris fustam in dicto loco ad usum similiter domorum Templi bayuliae Miraveti. Preterea retinemus nobis et successoribus nostris et castro Miraveti perpetuo omnes pinos donzeles qui sunt vel deinceps fuerint in termino dicti Mansi, ita quod ipsos pinos vel aliquem ex ipsis absque voluntate Comendatoris 
Miraveti numquam possitis scindere vel destruere vel eos inde amovere, et habeamus nos et successores nostri semper duas partes fructuum eorumdem, et vos et vestri tertiam partem. Item volumus quod vos et successores vestri laboretis bene et fideliter dictas possessiones et honores vestro posse, et si forte vos vel successores vestri dictas possesiones vel honorem seu partem ipsarum vendere vel alienare volueritis, quod detis fatigam nobis decem dierum secundum consuetudinem de Batea, et quod possideamus eas, si voluerimus, pro pretio vobis oblato libere retinere, quas nisi retinere voluerimus possitis eas vendere vel alienare vestris consimilibus habitatoribus in dicto loco, exceptis militibus atque sanctis, quibus dare seu vendere ac alienare aliquatenus non possitis. Pro qua autem donatione et concessione confitemur et recognoscimus habuisse et recepisse a vobis pro introitu D.C.C. solidos Jaccen. de quibus per pacatos nos tenemus, renuntiantes exceptioni pecuniae non traditae vel receptae et doli. Nos vero populatores predicti per nos et omnes successores nostros vobis promittimus et successoribus vestris et fratribus supradictis ac etiam Templo esse homines et vassalli fideles ac legales vestri et successorum vestrorum et etiam Templi. Promittimus etiam vobis et successoribus vestris et castro Miraveti facere et annuatim solvere dictum censum et dezimam et primitiam dare fideliter ac legaliter de honoribus et possessionibus supradictias secundum Consuetudinem de Batea, et dicta caficia medium ordei et medium frumenti dare et solvere pro qualibet pareliata annuatim in festo Sancti Michaelis Septembris, prout superius est expressum, et omnes alias conditiones et pacta superius comprehensa tenere et observare inviolabiliter et complere et nunquam in aliquo contravenire aliqua ratione.

Quod est actum sexto Idus Septembris anno Domini millessimo ducentessimo octagessimo.

Sig+num f. Petri de Monte Cathano, domorum Militiae Templi in Aragonia et Catalonia Magistri ac tenentis locum Magistri Ultramarini in tota Hispania. Sig+num f. Petri de Tous, Comendatoris Miraveti. Sig+num f.Eximenis de Lerida, Comendatoris Cantavechiae. Sig+num f. Dalmatii de Sero, Comendatoris Ambelli. Sig+num f. Guillelmi de Abelars, Comendatoris Derthusae. Sig+num f. Guillelmi de Benages, Comendatoris Ortae. Sig+num f. Guillermi de Solerio, Comendatois Riclae. Sig+num f. Raymundi de Villalba. Sig+num f. Raymundi de Sancto Danielo, sociii dicti Magistri. Sig+num f. Petri de Manresa, Vicarii Miraveti. Sig+num f. Fernandi Rotundi, fratris Capelani dicti Magistri predictorum, qui haec omnia et singula laudamus, concedimus et firmamus. Sig+num f. Bernardi de Regali, baiuli Ortae. Sig+num f. Petri Salvatoris de Regali. Sig+num Vitalis Sabaterii, habitatoris de Batea. Sig+num Paschalis Gueraldi. Sig+num Petri de Salto testium huius rei. Sig+num Raymundi Savine, notarii jurati Domini Magistri predicti qui haec de mandato ipsius Magistri et praedictorum fratrum escripsit et clausit die et anno praedicitis. 


\section{FONTS I BIBLIOGRAFIA}

\section{FONTS DOCUMENTALS}

A. Arxiu Històric Nacional (Madrid)

1. Secció d'Ordes Militars. Sant Joan de Jerusalem.

Castellania d'Amposta. Batllia de Miravet.

Carpetes: 306, 309 i 609.

Caixa: 8265 .

2. Secció de Manuscrits.

Manuscrit llatí 944 B. Text llatí de les «Constitutiones

Bajulie Mirabeti». Segle XIV.

B. Arxiu de la Corona d'Aragó (Barcelona)

1. Cancelleria Reial
a) Registres de Cancelleria.
Registres 310 i 587.
b) Pergamins.
Pergamins de Ramon Berenguer IV: 261.
Pergamins d'Alfons I el Cast: 320 i 321.
c) Vària de Cancelleria.
Registre 1.

2. Reial Patrimoni

Subsecció del Mestre Racional.

Volums: 541,2406, 2407, 2591, 2597, 2601, A-401 i A-403.

3. Reial Audiència

Subsecció de Plets Civils.

Núms. 7665 i 13170 (inèdits)

C. Arxiu Històric Provincial de Tarragona (Tarragona)

Protocols de Batea. Notari Jaume Ferrer. Anys 1750-1775.

Caixa núm. 5, núm. de registre general 2598. 


\section{BIBLIOGRAFIA}

Alanyà I ROIG (Josep), La Carta de Donació a Bernat Granell. Doble fur i catalanitat de Batea, "La Vila Closa», 8-9 (1988), pp. 91-97 i 103-110.

- El terme municipal: Pinyeres, «La Vila Closa», 16 (1990), pp. 187-195.

ARTEAga (Oswaldo), PADró (Josep) i SANMARTí (Enric), El poblado ibérico del Tossal del Moro de Pinyeres (Batea, Terra Alta, Tarragona), Barcelona, 1990 Institut de Prehistòria i Arqueologia. Diputació de Barcelona. Monografies Arqueològiques, núm. 7.

FONT I RIUS (Josep M."), Cartas de población y franquicia de Cataluña, 2 vols., Madrid-Barcelona, CSIC, 1969.

FUGUET I SANS (Joan), L'arquitectura de les capelles templeres a la Catalunya Nova, "Primeres Jornades sobre els Ordes Religioso-militars als Països Catalans», Montblanc, 1985. Publicat a «Aplec de Treballs», 9 (1989), Centre d'Estudis de la Conca de Barberà.

MADOZ (Pascual), Diccionario geográfico, estadístico, histórico de España y sus posesiones de Ultramar, Madrid, Imprenta del Diccionario, 1848-1850.

MASCARÓ (Antonio), Mis Memorias, Barcelona, Imprenta y Editorial Altés, s.l., 1948.

MORERA Llauradó (Emili), Provincia de Tarragona, volum de la Geografia General de Catalunya, dirigida per Francesch CARRERAS CANDI, Barcelona, s.a.

Ortega (Pascual), La Carta de Población de la Pobla de Massaluca (1295), "Acta Medievalia», 7-8 (1986-1987).

PAGAROLAS (Laureà), La Comanda del Temple de Tortosa: primer periode (11481213), Tortosa, Edit. Cooperativa Gràfica Dertosense, 1984.

VENTOSA I SERRA (Enric), Esglésies singulars de la Terra Alta, Tarragona, Institut d'Estudis Tarraconenses Ramon Berenguer IV, Diputació de Tarragona, 1986.

\section{RÉSUMÉ}

Voici des études faites sur le lieu, aujourd'hui dépeuplé, de Pinyeres (Terra Alta), qui dépend du bourg et terme municipal de Batea (Tarragone) depuis 1841; et au sujet de la charte de peuplement accordée par les templiers du château de Miravet. La charte de peuplement de Pinyeres, conférée en 1280, est aussi une charte agraire avec franchises, privilèges et obligations touchant les habitants, qui main- 
tiennent avec les seigneurs un lien féodal de vassalité. La concession seigneuriale de peuplement et le paiement du cens sont établis selon les coutumes de Batea. Il y a des réserves seigneuriales sur les pâturages, le bois, les pins pignons et leurs fruits en plus du droit de préemption. En vertu de la charte, les templiers ont, sur le lieu et sur ses habitants, la pleine juridiction civile et criminelle, mero et mixto imperio. Le texte de la charte, découvert par l'auteur, est divulgué ici pour la première fois. Jusqu'à présent, on ne connaissait que la brève référence que le docteur Josep $\mathbf{M}$. $^{2}$ Font i Rius en avait faite dans le premier volume de Varia de Cancelleria des Archives de la Couronne d'Aragon de Barcelone.

L'auteur donne une explication documentée de l'histoire du lieu dit de Pinyeres et en décrit l'enceinte urbaine, en faisant ressortir les édifices les plus représentatifs tels que l'église, le château, la prison, la place, le four communal et la butte de la potence, endroit où se dressait le gibet de pierre pour exécuter les condamnés à la peine capitale.

Dans un commentaire étendu et fourni sur le document juridique de peuplement, l'auteur explique aussi le changement de juridiction qu'a vécu Pinyeres au moment des partisans de Saint Jean, pendant le XVème siècle, quand, tout en faisant un échange avec les villes de Jatiel et de Samper de Calanda, Pinyeres et Nonasp passèrent de la juridiction du château de Miravet à celle du couvent de l'ordre de l'Hôpital de Caspe.

\section{SUMMARY}

The topic of this study is, on the one hand, the village of Pinyeres, nowadays depopulated (in the catalan area of the Terra Alta), that was annexed to the town and local administration of Batea (Tarragona) since 1841 and, on the other hand, the populating chart granted by the Templars of the castle of Miravet. Pinyeres' populating chart, granted in 1280 , is also an agrarian establishment chart with exemptions, privileges and duties for the inhabitants who have a feudal link of vassalage with the landlords. The seigniorial concession to populate and the payment of the rents obey the habits of Batea. There are seigniorial reserves on pasture; wood and stone pine including their fruit, besides the pre-emptive right. According to the chart, the Templars have full civil and criminal jurisdiction and «mero et mixto imperio" on the village and its inhabitants. The text of the chart, discovered by the author of this essay, is exposed here for the first time. Up to now, we only knew of a short reference in the first volume of Varia de Cancelleria of the Aragon Crown Archives in Barcelona, published by doctor Josep M." Font i Rius.

The author gives a well-documented explanation of the village of Pinyeres' history and describes the urban centre, giving a special emphasis to the most representative buildings such as the church, the castle, the jail, the village square, the public oven and the mound of the gallows where stone gallows stood to execute the men under sentence of death.

Using a long well-documented comment of the juridic populating chart, the 
author also explains the change of jurisdiction that the village of Pinyeres suffered when they passed to belong, during the $\mathrm{XV}^{\text {th }}$ century, to the partisans of Saint John. It is when exchanging the towns of Jatiel and Samper de Calanda, that Pinyeres and Nonasp passed from the jurisdiction of the castle of Miravet to that of the convent of the Order of the Hospital of Casp. 